\title{
1 Use of tube flow fractionation in wood powder characterisation
}

\section{Pasi Karinkanta*, Ossi Laitinen}

3 Faculty of Technology, Fibre and Particle Engineering, University of Oulu, Finland

$4 *$ corresponding author

5 Faculty of Technology, Fibre and Particle Engineering, P. O. Box 4300, FIN-90014 University of Oulu, Finland

$6 \quad$ E-mail: pasi.karinkanta@hotmail.com

\section{Abstract}

9 The size and shape of powdered wood particles are important properties when considering their use in wood burning or

10 the production of biofuels, biocomposites and biochemicals. Different measurement techniques can be used to measure

11 particle size, but unfortunately these do not provide information about the shape of the wood particles. In this study, a

12 fast and reliable tube flow fractionation method (analysing time 3min; particle size range $1 \mu \mathrm{m}-2000 \mu \mathrm{m}$; analysed

13 particles per sample 30,000-200,000) is used to separate water-diluted wood powders which varies by size and shape.

1430 different milled wood powder samples are analysed (average particle size from $20 \mu \mathrm{m}$ to $300 \mu \mathrm{m}$ and average aspect

15 ratio from 3 to 10). The major benefit in tube flow fractionation method is that the concealment of the finest particles in

16 CCD imaging is avoided by applying the imaging unit after the fractionation of wood particles. Wood powder can

17 easily be separated into different fractions by leading the water-diluted sample flow into different beakers for certain

18 time periods. The transmittance signal after tube flow fractionating yields information about the particle size, and

19 optical imaging provides information about the morphology of the particles. It was found in this study that rotor impact

20 milling to a finer size range produces small but elongated particles. Additionally there were only small differences in

21 the particle size distributions between jet milled and oscillatory ball milled samples, but it was noticed that oscillatory

22 ball milled powders have a significantly lower aspect ratio than jet milled samples.

23 Keywords: Aspect ratio, morphology, particle size, tube flow fractionation, wood, wood powder characterisation.

\section{1. Introduction}


Fine ground wood, that is, wood powders or flours, are sustainable raw materials that can be used in the production of bioenergy, biocomposites and chemicals that originate from cellulose, lignin and hemicelluloses. Knowledge is already available about the mechanical processing of wood into powdered forms [1-9] and their use in different applications involving burning [10,11], composite production [12-15] and the preparation of biochemicals and biofuels [16-19]. It is recognised that the size and shape of fine ground wood particles influence the chemical, enzymatic and thermochemical conversion of wood, but they also influence the mechanical properties of wood-based composites.

31 Particle size measurement by sieving or laser diffraction offers a way to obtain knowledge about the particle size distribution. Particle diameter in these methods is evaluated from the laser diffraction pattern or from the screen aperture, where particle size is typically characterised by one value. To obtain knowledge about the shape, various static microscopic methods are typically utilised. The major drawback of these methods is that in order to obtain statistically reliable results is very laborious. One of the most promising techniques of size and shape measurement is to take hundreds or thousands of photographs of the free flowing powder with a charged coupled device (CCD) and to measure particle shape by using image analysing software. However, the drawback of this imaging method is that the finest particles in the investigated sample are easily hidden or concealed by larger ones during image capture. Another common problem is that it is impossible to distinguish the shape of very fine particles when the particle size is close to the resolution limit. But when particles cannot be imaged optically, other microscopic methods can be used, such as electron microscopy. In the imaging of the finest particles with electron microscopy, as well as with other methods, there is also a problem that the particles are easily hidden or concealed behind larger particles. In order to solve above-mentioned difficulties, the tube flow fractionation method together with the use of an imaging unit (CCD) has been found to be a suitable method for measuring the morphology of different wood fibres [20]. After fractionation, the largest particles are separated from the finest, and the concealment of the finest particles can be avoided during imaging. Tube flow fractionation can also be used to separate samples into different fractions by size and shape [21,22], which can be further analysed and used, for example, in enzymatic hydrolysis. This makes it possible to analyse the largest particles separately by using optical microscopy and the finest particles by using electron microscopy. However, there is not yet published detailed knowledge of whether the tube flow fractionation works with wood powders or how well it can be applied in their characterisation.

51 In this work, different sized and shaped wood powders originating from Norway spruce (Picea abies) wood are investigated with the tube flow fractionation method. The fractionated samples are characterised by measuring the light transmittance of a light-emitting diode (LED, $\lambda=450 \mathrm{~nm}$ ) and the particle dimensions from photographs captured with 
54 a CCD camera. In this research, it is proven that tube flow fractionating separates fine wood powders by their size and

55 shape. Wood powder can easily be separated into different fractions by leading the water-diluted sample flow into

56 different beakers for certain time periods. The transmittance signal after tube flow fractionating yields information about the particle size, and optical imaging provides information about the morphology of the particles.

\section{2. Materials and methods}

\subsection{Raw materials and mechanical processing}

The raw material was Norway spruce (Picea abies) sawdust produced at Seikun saha (Pori, Finland), which is located in

61 Western coast of Finland $\left(61^{\circ} 29^{\prime} \mathrm{N}, 021^{\circ} 48^{\prime} \mathrm{E}\right)$ and delivered to the University of Oulu. After delivery, the sawdust was stored in a freezer. After storage, the sawdust was dried in an oven at a temperature below $105{ }^{\circ} \mathrm{C}$ and was sieved with a vibrating screen using an aperture size of $4 \mathrm{~mm}$. The particles that could not get past the screen were rejected from the sample.

Milling of the dried and screened sawdust was accomplished with an air classifier mill, where a rotor impact mill 50 ZPS (Hosokawa Alpine, Germany) was integrated with an air classifier 100 ATP (Hosokawa Alpine, Germany) by using different operating parameters (see Table 1). For further information about operating parameters on particle properties, see [23]. Air classifier milling was used also as pregrinding for jet and oscillatory ball milling experiments. In pregrinding, the finest particles were removed from the milled sample with air classification using the air classifier 100 ATP alone. The milling of preground samples was accomplished with an oscillatory ball mill CryoMill (Retsch, Germany) and a fluidised bed jet mill 100 AFG (Hosokawa Alpine, Germany) which was also integrated with the air classifier 100 ATP. For further information about the operating parameters on the product properties in these fine grinding mills, see $[24,25]$. 
Table 1. Morphology characteristics of rotor impact milled wood powders. The quantity $d_{\mathrm{LS}, 50}$ refers to the median particle size measured by using the laser diffraction method.

\begin{tabular}{llll}
\hline Milling/classification & Feed & Varied operating parameters & Sample naming \\
\hline Air classifier mill & $\begin{array}{l}\text { Dried and screened } \\
\text { sawdust }\end{array}$ & $\begin{array}{l}\text { Rotor speed, classifier speed } \\
\text { and impact angle }\end{array}$ & RM $\left(d_{\text {LS,50 }}\right)$ \\
$\begin{array}{l}\text { Air classifier mill and post- } \\
\text { classification }\end{array}$ & $\begin{array}{l}\text { Dried and screened } \\
\text { sawdust }\end{array}$ & $\begin{array}{l}\text { Rotor speed, classifier speed } \\
\text { and impact angle }\end{array}$ & RM+AC $\left(d_{\text {LS,50 }}\right)$ \\
$\begin{array}{l}\text { Jet mill integrated with air } \\
\text { classifier }\end{array}$ & RM+AC & $\begin{array}{l}\text { Grinding air pressure, } \\
\text { classifier speed }\end{array}$ & JM $\left(d_{\mathrm{LS}, 50}\right)$ \\
Oscillatory ball mill & RM+AC & Milling time & OBM $\left(d_{\mathrm{LS}, 50}\right)$ \\
\hline
\end{tabular}

\subsection{Preparation of diluted wood powder suspensions}

81 One gram of the produced wood powder was diluted with deionised water in order to form $0.2 \%$ particle concentration.

82 Before dilution, the wood powder was dispersed by mixing $1 \mathrm{~cm}^{3}$ of a dispersant per $100 \mathrm{mg}$ of the wood (dry mass).

83 The dispersant was prepared by diluting $2.5 \mathrm{~g}$ of Sokalan CP 5 (BASF) with $500 \mathrm{~cm}^{3}$ of deionised water. The diluted

84 sample was stirred for at least 30 min with a magnetic stirrer and held for 6 min in an ultrasonic bath to ensure complete

85 dispersal. Diluted and dispersed samples were applied for particle size measurement and tube flow fractionation.

86 In general, the amount of shrinking and swelling which takes place is directly proportional to moisture content changes

87 in the wood. Wood pieces shrinks and swells the greatest amount in the tangential direction and about half as much in

88 the radial direction (about 5\%), and about $0.1 \%$ to $0.2 \%$ in the longitudinal direction [26]. Even if swelling increase

89 slightly particle size of analysed wood particles, this is not very significant source of error in practice. Pre-treatment of

90 samples were always similar and run in liquid mode with both devices (Tube flow fractionation method versus Laser

91 diffraction method) in order to better comparison of methods.

\subsection{Particle size distribution}

93 Volumetric particle size distribution was measured according to standard ISO 13320 [27] with an LS 13320 analyser

94 (Beckmann Coulter). Laser diffraction-based volumetric particle sizes were marked as $d_{\mathrm{LS}, \mathrm{Xx}}$, where ' $\mathrm{XX}$ ' stands for the 95 percentages in the cumulative distribution. 


\subsection{Tube flow fractionation}

99 Fractionation equipment has been presented earlier (see [22]), and this study utilises the same equipment and fractionation conditions. Fig. 1 presents a schematic picture of the tube flow fractionation equipment. The material of

101 the tube is Teflon, and counterpressure during fractionation is $200 \mathrm{kPa}$. The theory of the fractionation principle has been described in more detail in [28]. In briefly when the sample is injected into the tube, the particles are distributed randomly. As the flow begins and proceeds, the slight turbulence in the transition flow regime begins to move the particles randomly inside the flow. The probability of being captured by the faster middle flow is higher for particles with one long dimension (e.g. high aspect ratio) or multiple long dimensions (e.g. flake type particles or large sawdust) than for particles with short dimensions (e.g. fines or small sawdust). Thus, the large particles tend to concentrate at the front end of the flow and finally come out from the tube first.

Fig. 1.

A $5 \mathrm{~cm}^{3}$ sample at a consistency of $0.2 \%$ was fractionated with deionised water for 100 seconds at an average flow rate of $(7.3-8.5) \mathrm{cm}^{3} \mathrm{~s}^{-1}$ in a long plastic tube (diameter $4 \mathrm{~mm}$ ) to separate the particles according to their size. The

111 temperature of the suspensions stayed between $20.9^{\circ} \mathrm{C}$ and $23.0^{\circ} \mathrm{C}$ during tube flow fractionation. The Reynolds number for the water flow was $2200-3100$ in the experiments. The variables of interest during fractionation, including

113 flow velocity, pressure, temperature, sample volume, and consistency, are all maintained precisely at a constant level, as each variable has a direct effect on the fractionation. When keep fractionation conditions constant, certain particle sizes

115 always exit the flow tube at the same time and this ensures that repeatability and reliable of tube flow fractionation methods is very good. The variation (standard deviation) of the combined sample fractionation and optical image

117 analysis has been determined to be $4.5 \%$ and based on 23 parallel sample analysis [22]. Tube flow fractionation 118 technique is use also in commercial pulp analysator (Valmet MAP - Valmet Pulp Analyzer, Valmet Automation), which 119 is the online measurement of micro-scale details of fiber properties, including fibrillation, vessel segments, flocs and other particles [29].

\subsection{Transmittance signal}

122 After the fractionation of the sample, the signal detection unit, RM3 (Valmet Automation, Finland) was activated (see 123 Fig. 1) where $\operatorname{LED}(\lambda=450 \mathrm{~nm})$ was used as the light source. In total, 2200-2600 transmittance signal values were 124 collected while the sample flowed through the RM3- LED and transmittance signal detection unit. The zero positions of 

beginning and the end of the signal (see Fig. 2b) were also removed due to random disturbance at the beginning of the

127 signal. The restricted signal was then normalised to $100 \%$, and the time count was started from the beginning of the 128 restricted signal (Fig. 2c).

129 Fig. 2.

\subsection{Optical microscopy by CCD camera}

131 The wood particles in the fractionated particle-water suspension were visualised with a high-definition CCD camera

132 unit (Basler acA1400-30gm, Germany) which captured approximately 1000 individual pictures including between

133 30,000-200,000 individual particle analysed per sample point (see Fig. 1). Image analysis of individual particles was

134 accomplished by applying a Metso IMG image analysis software (Valmet Automation, Finland) and practically image

135 analysis measurement sensitivity is around $1 \mu \mathrm{m}$. Image analysis procedure can be divided in six various steps: (1)

136 image formation, (2) image scanning, (3) feature detection (count, shape, size etc.), (4) feature analysis, (5) data

137 processing and (6) data presentation. Image analysis procedure has been clarified in Appendix A. Fig. 3 presents three 138 example pictures and the transmittance signal of a wood powder sample taken after tube flow fractionation. The 139 photographs obtained with the CCD camera were used to evaluate the cumulative projected area based the projected 140 area diameter

$$
d_{\mathrm{P}}=2 \sqrt{\frac{A}{\pi}}
$$

142 and the aspect ratio

$143 \quad \mathrm{AR}=a / b$.

144 In equations (1) and (2), $A$ is the projected area of the particle, $a$ is the maximum Feret's diameter of the projected

145 particle and $b$ is

$$
b=\frac{A}{\pi a} .
$$

\section{Fig. 3.}




\section{Results and discussion}

\subsection{Comparison of measurement techniques}

151 The measurement process starts not with the actual measurement, but with the sampling. The sample is usually a small

152 sub-volume of an entire process batch. In order to obtain relevant information about batch, the sample needs to be

153 representative. Spinning Riffler device has been used in this research in order to have representative samples from wood

154 particles. It is also essential that all samples are well dispersed (see Chapter 2.2.), as agglomerates may plug the flow

155 channel or misrepresent the actual results.

156 Traditionally, particle characterization methods have been gravimetric. However, since mesh screening does not

157 produce fractions with sharp size limits, gravimetric techniques only give approximate information about particle size.

158 The flow cytometer (FCM) is one potential method, but main limitations of this methods is quite narrow size range

159 (from approximately $0.2 \mu \mathrm{m}$ to $100 \mu \mathrm{m}$ ) and plenty of samples analysed in this research had particle size over that limit.

160 The optical imaging methods are very suitable for analysing of particles like wood powders, because wood particles are

161 typically proper size and contrast between background and wood particles are evident (i.e. grey vs. black). In the

162 execution of the measurement, enough particles must be measured to give good statistics; typically several thousand, so

163 30,000-200,000 individual particle has been analysed per sample point in this research. Many measurement techniques

164 have international standard procedures that can be followed to ensure reproducible results. In addition determination of

165 aspect ratio of wood particles are focused in this research and method based on laser scattering is not possible to analyse

166 aspect ratio but only sphere-equivalent diameter (SED). Table 2 summarise some measurement techniques, which can

167 be used for particle size characterisation.

Table 2. Some measurement techniques, which can be used for particle size characterisation. The output size is the given size property, for example circle- or sphere-equivalent diameter (CED, SED).

\begin{tabular}{llll}
\hline Technique & Size range & Output size & Principle \\
\hline Sieve & $>20 \mu \mathrm{m}$ & Upper and lower limit of size & Gravimetric \\
& & & \\
Flow cytometry & $0.2-100 \mu \mathrm{m}$ & CED, SED & Optical \\
saser diffraction & $40 \mathrm{~nm}-2000 \mu \mathrm{m}$ & SED & Optical \\
Static microscopy & $>1 \mu \mathrm{m}$ & Length, area, volume, aspect & $\begin{array}{l}\text { Optical } \\
\text { imaging }\end{array}$
\end{tabular}


Tube flow fractionation + image analysis

$1 \mu \mathrm{m}-2000 \mu \mathrm{m}$ (particle size), $10 \mu \mathrm{m}-$ $2000 \mu \mathrm{m}$ (aspect ratio)
Length, area, volume, aspect ratio
Optical imaging

\subsection{Different sized wood powders}

Fig. 4 shows particle sizes of various wood samples analysed with tube flow fractionation method (based on image analysis) and laser diffraction method (based on optical scattering). Particle size of wood powders increased quite logically with both methods (image analysis and laser diffraction). Nevertheless same particle size was measured with laser diffraction (for instance around $200 \mu \mathrm{m}$ ), even if average aspect ratio varies from 7 to 10 . That is because method based on laser scattering is not take account of aspect ratio of particles. It has to also noted that image analysis particle size based on planar surface of particle while laser diffraction based on sphere-equivalent diameter (SED).

\section{Fig. 4.}

Fig. 5 shows the particle size distributions of various rotor impact milled (RM) wood powders and rotor impact milled wood powder that has been classified after milling $(\mathrm{RM}+\mathrm{AC})$. In the case of the classified sample (RM+AC), two replicated measurements were done on a single sample. The particle size distribution of the RM samples with the median particle size over $200 \mu \mathrm{m}$ was cut at the large end, which means that there were particles larger than $2 \mathrm{~mm}$ present in these samples. In Fig. 5, when comparing the non-classified sample having a $d_{\mathrm{LS}, 50}$ of $202.6 \mu \mathrm{m}$ with the classified sample having a $d_{\mathrm{LS}, 50}$ between $194.3 \mu \mathrm{m}$ and $202.8 \mu \mathrm{m}$, it can be seen that the width of the particle size distribution of the classified sample was narrower.

\section{Fig. 5.}

It has been noted that tube flow fractionation classifies particles primarily according to their hydrodynamic length [30,31], but particle width and thickness have a smaller but still statistically significant effect on fractionation time [21]. Fig. 6 shows the normalised LED transmittance signal after tube flow fractionation of the wood powder samples. In Fig. 6 can be seen single- or double-peaked signal profiles, depending on the median particle size of the wood powders. The signal peak occurring during the first $3 \mathrm{~s}$ is called the $1^{\text {st }}$ peak, and the signal peak occurring after the first $3 \mathrm{~s}$ is the $2^{\text {nd }}$ peak. Fig. 6 shows the cumulative projected area-based distributions as a function of $d_{\mathrm{P}}$ and the aspect ratio (AR), by considering three different cases for each sample: the whole sample, only the particles from Fig. 5 (particle group 1, PG1) which flow during first the $3 \mathrm{~s}$ and only the particles in Fig. 5 (particle group 2, PG2) which flow after $3 \mathrm{~s}$. The cumulative area distributions of all other RM and RM+AC samples are shown in Appendix B (Figs. B.1-B.6). 
According to Figs. 7, B.1-B.6, the cumulative projected area of PG1 is composed mainly of particles with a larger $d$ P and AR than in the case of a whole sample or PG2. On the other hand, the projected area of PG2 is composed of particles with a smaller $d_{\mathrm{P}}$ and AR in comparison to the whole sample (Figs. 7, B.1-B.6). Between the RM samples, there are substantial differences in $d_{\mathrm{P}}$ and AR values when considering only PG1 or the whole sample, but there are only small differences when considering only PG2 (Figs 7 and B.1-B.6). The differences in the cumulative area distribution between the whole sample and PG2 diminish as $d_{\mathrm{LS}, 50}$ decreases in the case of the RM samples (Figs. 7 and B.1-B.6). For the RM samples, PG2 comprises a much larger area in the transmittance signal when $d_{\mathrm{LS}, 50}$ decreases (Fig. 6). This can be interpreted so that the whole sample is more like PG2 as the $d_{\mathrm{LS}, 50}$ decreases. Therefore, it is very logical that the particle size and shape differences between the whole sample and PG2 diminish as $d_{\mathrm{LS}, 50}$ decreases in the case of the RM samples. In the case of the classified sample (RM+AC), the removal of fine particles makes the signal area of PG2 even smaller in comparison to the RM samples with larger $d_{\mathrm{LS}, 50}$ (Figs. 7, B.1-B.6). This can be interpreted so that in the case of RM+AC, the whole sample is more like PG1 than in the case of the RM samples. The reason for this is that in the case of $\mathrm{RM}+\mathrm{AC}$, the finest particles have been removed after milling. Therefore, it is logical that the classified sample has the foremost difference in the cumulative area distributions between the whole sample and the PG2 (Fig. 7, B.1-B.6). According to the results (Figs 7, B.1-B.6), tube flow fractionation classifies fine wood particles by size and shape. The transmittance signal of fractionated samples (Fig. 6) provides insight about the particle size of wood powders, where the presence of the $1^{\text {st }}$ peak indicates the presence of large particles, and the presence of the $2^{\text {nd }}$ indicate the presence of fine particles. By considering the particle size distributions of the $\mathrm{RM}+\mathrm{AC}$ sample, which has no $2^{\text {nd }}$ signal peak (Fig. 6), and the 'RM (23.4 $\left.\mu \mathrm{m}\right)$ ' sample, which has a negligible $1^{\text {st }}$ peak (Fig. 6) in Fig. 5, the large particles could be arbitrarily considered as the particles with a $d_{\mathrm{LS}}$ over $50 \mu \mathrm{m}$ and the fine particles as those with a $d_{\mathrm{LS}}$ less than $50 \mu \mathrm{m}$. Median particle sizes $\left(d_{\mathrm{LS}, 50}\right)$ could not be evaluated directly from the transmittance signal due the differences in the transmittance signals between the RM and RM+AC samples with a similar $d_{\mathrm{LS}, 50 \text {. }}$

\section{Fig. 6.}

\section{Fig. 7.}

From Figs. 7, B.1-B.6 it can be seen that the particles with an aspect ratio of 1 comprise approximately 10\% (AR10) or an even larger projected area in the case of the whole sample and PG2. In Fig. 8, aspect ratios of the particle are shown as a function of $d_{\mathrm{P}}$, where samples are grouped into four (I-IV) different groups. According to Fig. 8, the smallest particles with a $d_{\mathrm{P}}$ lower than $10.7 \mu \mathrm{m}$ all have aspect ratios of 1 . It is very unlikely that wood particles form a perfect 
circle shape during mechanical processing, and therefore, it is suggested that particles having an aspect ratio of 1 are too small for reliable shape recognition. When considering the particle size ranges of $d_{\mathrm{LS}, 50}>200 \mu \mathrm{m}$ (group II in Fig. 8) and $d_{\mathrm{LS}, 50}$ between $47 \mu \mathrm{m}$ and $52 \mu \mathrm{m}$ (group III in Fig. 8), it can be seen that milling to a finer particle size range can produce elongated particles (AR $>10$ ) in the particle size range $d_{\mathrm{P}}>80 \mu \mathrm{m}$. Milling to an even finer particle size range, $d_{\mathrm{LS}, 50}<35 \mu \mathrm{m}$ (group IV in Fig. 8), can produce elongated particles (AR > 10) with $d_{\mathrm{P}}$ between $65 \mu \mathrm{m}$ and $80 \mu \mathrm{m}$ (Fig. 8). This means that rotor impact milling to a finer size range produces smaller elongated particles. In Fig. 8, the shapes of the RM samples in the particle size range $d_{\mathrm{P}} \leq 20 \mu \mathrm{m}$ are very similar. One probable reason for this is that the shapes of the particles cannot be distinguished from others in this particle size range. The morphology of the classified sample (RM+AC) is different from that of the RM samples, especially when $d_{\mathrm{P}}>20 \mu \mathrm{m}$ (group I in Fig. 8).

\section{$231 \quad$ Fig. 8.}

\subsection{Comparison of wood powders having different morphology}

233 Jet milling and oscillatory ball milling can be used to produce wood powders having a similar $d_{\mathrm{LS}, 50}$ but different shapes 234 and relative degree of cellulose crystallinity [25]. Therefore, both jet milled (JM) and oscillatory ball milled (OBM) 235 samples are taken under consideration where in both cases, the feed material has been RM+AC. Fig. 9 shows the 236 differential volume-based particle size distributions of jet milled and oscillatory ball milled samples. When comparing 237 jet milled and oscillatory ball milled samples, it can be seen that there are very small differences in the particle size 238 distributions between samples that have $d_{\mathrm{LS}, 50}$ close to each other.

\section{Fig. 9.}

240 Fig. 10 shows the transmittance signal of fractionated JM and OBM samples. As in the case of rotor impact milled 241 wood (Fig. 6), there can again be distinguished single- and double-peaked profiles independent from the used milling 242 technique. It can also be seen that the area covered by the transmittance signal increases after $3 \mathrm{~s}$, while the $d_{\mathrm{LS}, 50}$ 243 decreases (Fig. 10). There are only very small or negligible differences in the signals between milling techniques (Figs.

2446 and 10). The largest difference in the signals between milling techniques seems to be the time where the $2^{\text {nd }}$ signal 245 peak occurs in the finest samples; in the jet milled and rotor impact milled samples, the $2^{\text {nd }}$ peak can be found right 246 before $8 \mathrm{~s}$ (Figs. 6 and 10), but for the oscillatory ball milled samples, it is right after $8 \mathrm{~s}$ (Fig. 10).

Fig. 10. 
Fig. 11 shows the cumulative projected area distributions as a function of $d_{\mathrm{P}}$ and the aspect ratio for jet and oscillatory ball milled samples with $d_{\mathrm{LS}, 50}$ close to each other. Appendix B (Figs B.7-B.15) shows the cumulative projected area distributions as a function of $d_{\mathrm{P}}$ and $\mathrm{AR}$ for all investigated jet and oscillatory ball milled samples. The cumulative area distributions of the JM and OBM samples (Figs. 11, B.7-B.15) show similar kinds of trends as a function of $d_{\mathrm{LS}, 50}$, as was discussed earlier in the case of rotor impact milled wood powders (see Section 3.1). In Fig. 12, when comparing jet milled and oscillatory ball milled samples with a $d_{\mathrm{LS}, 50}$ close to each other, it can be seen that oscillatory ball milled powders have a significantly lower aspect ratio. This can be observed from the CCD photos shown in Fig. 12, where the jet milled powders seem to retain an elongated shape. This information cannot be interpreted from the differential particle size distribution (Fig. 9) or from the signals (Fig. 10). When comparing the cumulative projected area distributions as a function of $d_{\mathrm{P}}$ between samples OBM $(20.3 \mu \mathrm{m})$ and JM $(19.9 \mu \mathrm{m})$, the oscillatory ball milled PG1 seem to have a significantly larger $d_{\mathrm{P}}$ (Fig. 11). It is suggested that this is due to the rounder or more flake-shaped particles in the OBM $(20.3 \mu \mathrm{m}) \mathrm{PG} 1$, which has a larger projected area in comparison to the elongated particles in JM $(19.9 \mu \mathrm{m})$ PG1 (Fig. 11).

Fig. 11.

According to Fig. 12, aspect ratio as a function of $d_{\mathrm{P}}$ follows a different trend for JM samples than for OBM samples, even when their $d_{\mathrm{LS}, 50}$ are close to each other. Therefore, it seems that jet milling favours the production of small and elongated particles, whereas oscillatory ball milling favours the production of rounder particles (Fig. 12). All of the OBM samples can be found in groups I-III, and the samples with $d_{\mathrm{LS}, 50}>44 \mu \mathrm{m}$ are located very close to the border of group I.

\section{Fig. 12.}

\subsection{Separation of wood powder to different size fractions}

269 With the imaging technique used, the differences in the shapes between wood powders were distinguishable when $d_{\mathrm{P}}>$

$27020 \mu \mathrm{m}$. Therefore, it seems that particles with $d_{\mathrm{P}} \leq 20 \mu \mathrm{m}$ would need measurement techniques, such as electron 271 microscopy, that can distinguish the shapes of these very small particles. According to Fig. 13, these particles do not 272 make a significant contribution in PG1 and have the highest signal peak after $10 \mathrm{~s}$. Therefore, the largest particles 273 including undispersed or agglomerated particles, which are found in PG1, can be fractionated by tube flow fractionating 274 without affecting the particles with $d_{\mathrm{P}} \leq 20 \mu \mathrm{m}$ according to image analysis. In addition the largest particles can also be 
offers a simply and fast way to separate the largest particles from the smallest, where the morphology of the largest particles can be distinguished from CCD photos. The finest particles, which are too small to be distinguished by optical microscopy, can be physically removed from the flow to their own fraction.

Fig. 13.

\section{Conclusions}

Tube flow fractionation classifies fine wood particles by size and shape. Transmittance measurement after tube flow fractionation can be used to provide insight about the particle size distribution of wood powders. An optical imaging device connected to the tube flow fractionation equipment provide an excellent and non-laborious method to measure the morphology of visually recognisable fine wood particles. Tube flow fractionation prior to optical imaging helps to avoid concealment of the finest particles behind the larger particles. Tube flow fractionation can also be used to separate wood particles into different particle size classes for further analyses and use.

\section{Acknowledgements}

The authors gratefully acknowledge the technical support provided by Metso and Valmet and the language services provided by Scribendi.

\section{REFERENCES}

[1] D.N.-S. Hon, W. Glasser, The effect of mechanical action on wood and fiber components, Tappi. 62 (10) (1979) 107-110.

[2] M. Himmel, M. Tucker, J. Baker, C. Rivard, K. Oh, K. Grohmann, Comminution of biomass: hammer and knife mills, Biotechnol. Bioeng. Symp. (1986) 39-58.

[3] D.J. Schell, C. Harwood, Milling of lignocellulosic biomass, Appl. Biochem. Biotechnol. 45 (1) (1994) 159-168.

[4] R.J. Gravelsins, Studies of grinding of wood and bark-wood mixtures with the Szego mill [PhD thesis], University of Toronto, 1998. https://tspace.library.utoronto.ca/handle/1807/12007 (accessed February 3, 2015).

[5] I.V. Mikushina, I.B. Troitskaya, A.V. Dushkin, Y.A. Ol'khov, N.G. Bazarnova, Transformations of wood structure under mechanochemical treatment, Chem Sustain Dev. 11 (2) (2003) 363-370.

[6] S. Paulrud, J.E. Mattsson, C. Nilsson, Particle and handling characteristics of wood fuel powder: effects of different mills, Fuel Process. Technol. 76 (1) (2002) 23-39.

[7] L.S. Esteban, J.E. Carrasco, Evaluation of different strategies for pulverization of forest biomasses, Powder Technol. 166 (2006) 139-151.

[8] Kobayashi N., Sato T., Okada N., Kobayashi J., Hatano S., Itaya Y., Mori S., Evaluation of wood powder property pulverized by a vibration mill, J. Jpn. Inst. Energy. 86 (9) (2007) 730-735.

[9] P. Karinkanta, Dry fine grinding of Norway spruce (Picea Abies) wood in impact-based fine grinding mills [PhD thesis], University of Oulu, 2014. http://herkules.oulu.fi/isbn9789526207193/isbn9789526207193.pdf.

[10] T. Adams, D. Raymond, C. Schmid, Optimization of a swirl burner for pulverized-wood fuels, Tappi. 71 (5) (1988) 91-96. 
[11] J.J. Reuther, G.G. Karsner, S.T. Jack, Plane flame furnace combustion studies of pulverized wood, in: Fundam. Thermochem. Biomass Convers., Springer, n.d.: pp. 793-810. http://doi.org/10.1007/978-94-009-4932-4_42.

[12] N.M. Stark, M.J. Berger, Effect of particle size on properties of wood-flour reinforced polypropylene composites, in: Fourth Int. Conf. Woodfiber-Plastic Compos. Madison-WI USA For. Prod. Soc. May, 1997: pp. 134-143. http://128.104.77.228/documnts/pdf1997/stark97d.pdf (accessed February 3, 2015).

[13] N.M. Stark, R.E. Rowlands, Effects of wood fiber characteristics on mechanical properties of wood/polypropylene composites, Wood Fiber Sci. 35 (2) (2003) 167-174.

[14] A. Isa, T. Toyoda, S. Suzuki, Y. Kojima, H. Ito, R. Makise, M. Okamoto, The Effects of Wet-Milled Wood Flour on the Mechanical Properties of Wood Flour/Polypropylene Composites, J. Wood Chem. Technol. 34 (1) (2014) $20-30$.

[15] M. Su, J. Chen, Z. Pan, X. Li, A. Xu, J. Hong, Study on the preparation and mechanical properties of injectionmoulded wood-based plastics, J. Appl. Polym. Sci. 132 (5) (2015) 41376.

[16] J.C. Pew, P. Weyna, Fine grinding, enzyme digestion, and the lignin-cellulose bond in wood, Tappi. 45 (3) (1962) $247-256$.

[17] M.A. Millett, M. Effland, D.F. Caulfield, Influence of fine grinding on the hydrolysis of cellulosic materials acid vs. enzymatic, Adv. Chem. Ser. 181 (1979) 71-89.

[18] N. Kobayashi, P. Guilin, J. Kobayashi, S. Hatano, Y. Itaya, S. Mori, A new pulverized biomass utilization technology, Powder Technol. 180 (3) (2008) 272-283.

[19] S. Mori, Development of utilization technologies of biomass energy, J Env. Eng Manage. 19 (2) (2009) 67-72.

[20] A. Haapala, O. Laitinen, P. Karinkanta, H. Liimatainen, J. Niinimäki, Optical characterisation of size, shape and fibrillarity from microfibrillar and microcrystalline cellulose, and fine ground wood powder fractions, Appita J. 66 (4) (2013) 331-339.

[21] O. Laitinen, K. Kemppainen, T. Stoor, J. Niinimäki, Fractionation of pulp and paper particles selectively by size, BioResources. 6 (1) (2011) 672-685.

[22] O. Laitinen, J. Niinimäki, Fractional study of the microfibrillated cellulose, Tappi J. 13 (7) (2014) 49-55.

[23] P. Karinkanta, M. Illikainen, J. Niinimäki, Pulverisation of dried and screened Norway spruce (Picea abies) sawdust in an air classifier mill, Biomass Bioenerg. 44 (2012) 96-106.

[24] P. Karinkanta, M. Illikainen, J. Niinimäki, Impact-based pulverisation of dried and screened Norway spruce (Picea abies) sawdust in an oscillatory ball mill, Powder Technol. 233 (2013) 286-294.

[25] P. Karinkanta, M. Illikainen, J. Niinimäki, Effect of different impact events in fine grinding mills on the development of the physical properties of dried Norway spruce (Picea abies) wood in pulverisation, Powder Technol. 253 (2014) 352-359.

[26] C.A. Eckelman, The shrinking and swelling of wood and its effect on furniture, Purdue University Cooperative Extension Service, 1998. http://www.academia.edu/download/31642553/FNR-163.pdf (accessed November 22, 2016).

[27] ISO 13320:2009(en): Particle size analysis — Laser diffraction methods, (n.d.).

[28] O. Laitinen, Utilisation of tube flow fractionation in fibre and particle analysis [PhD thesis], University of Oulu, 2011.

[29] O. Laitinen, I. Joensuu, T. Niskanen, J. Niinimäki, Analysis of the external fibrillation, Int Papwirtsch. 57 (10) (2014) 46-52.

[30] R. Pascal, J. Silvy, Hydrodynamic fractionation applied to characterization of paper pulp, Récent Prog. En Génie Procédés. 7 (1993) 233-238.

[31] B. Krogerus, K. Fagerholm, L. Löytynoja, Analytical fractionation of pulps by tube flow, Pap Puu-Pap Timber. 85 (4) (2003) 209-213. 


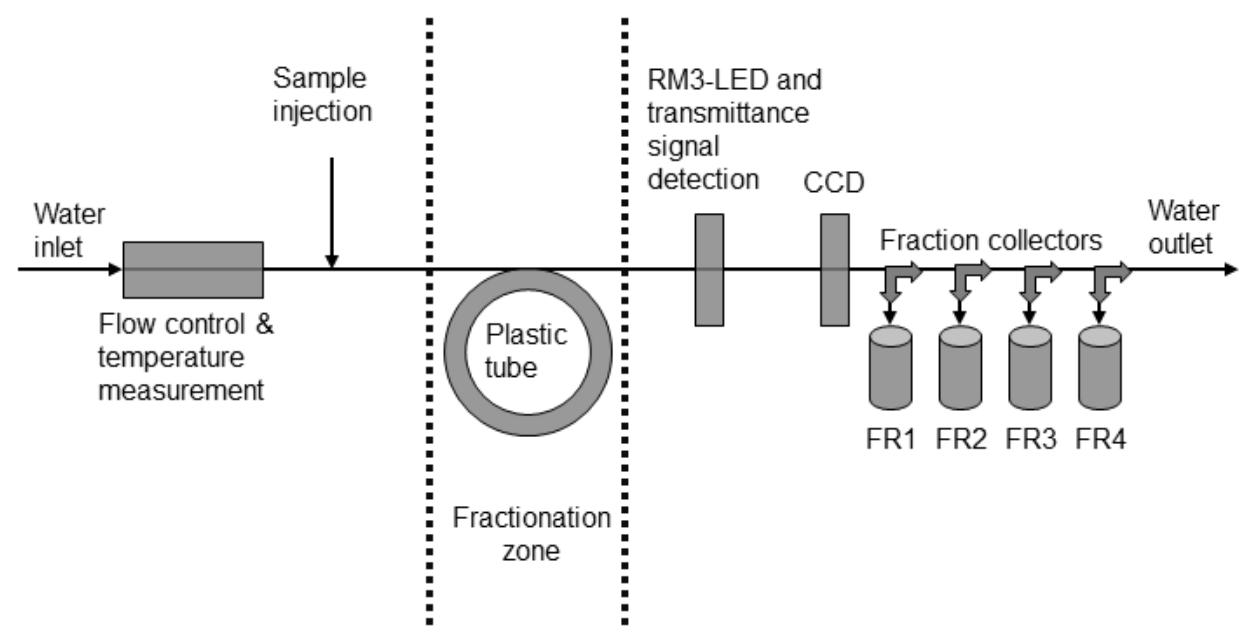

357 Fig. 1. Schematic picture of the fractionation equipment. In the figure 'FR1', 'FR2', 'FR3' and 'FR4' are containers 358 where different fractions of the fractionated sample are poured in.
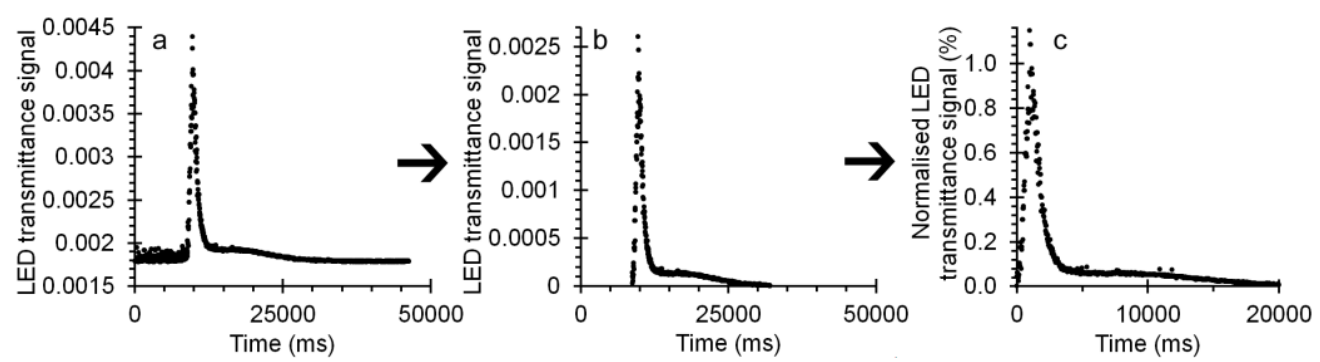

360 Fig. 2. Signal treatment procedure a) the original LED transmittance signal of one RM sample after tube flow

361 fractionation, b) the signal after zero position correction and restriction and c) the normalised signal where the time

362 starts counting from the beginning of the restricted signal. 


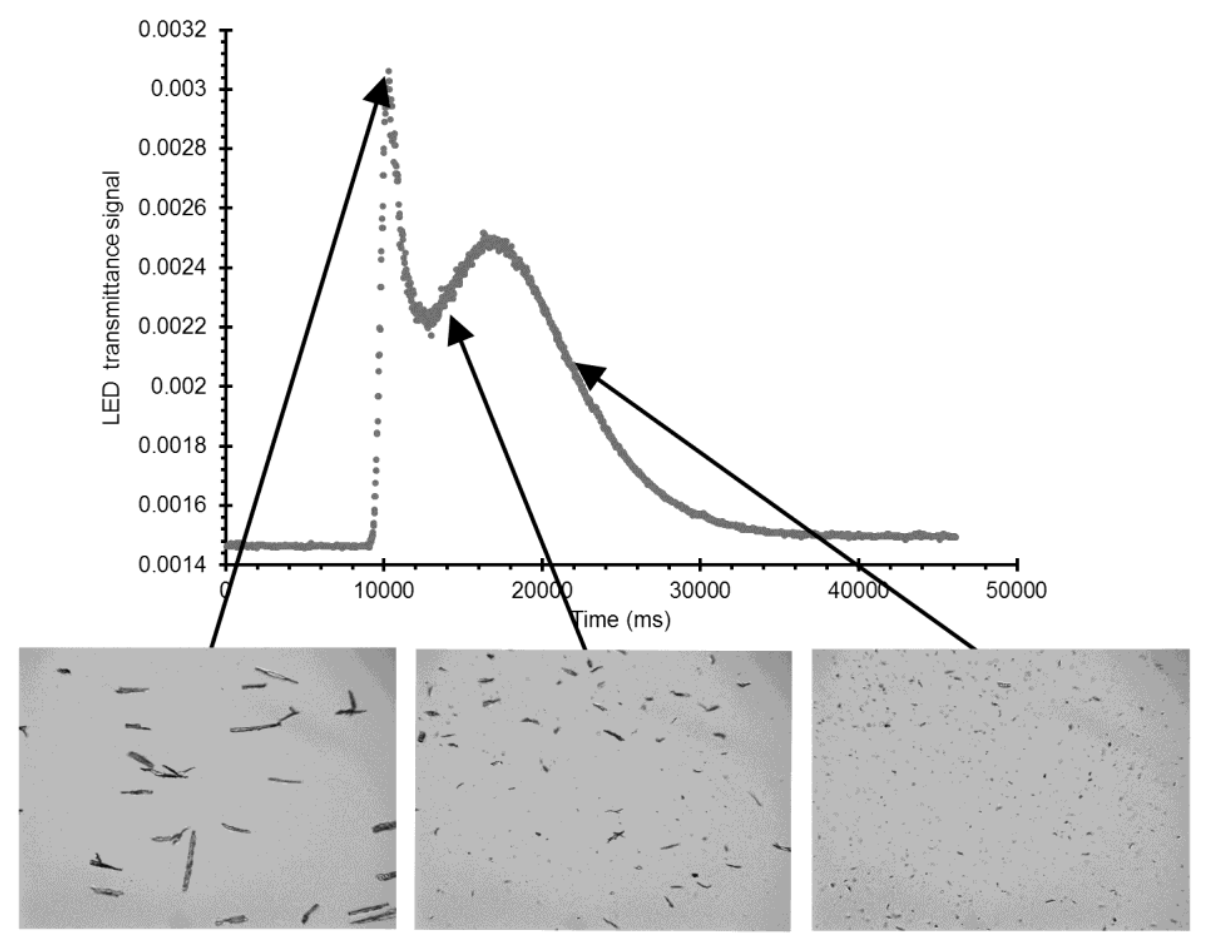

364 Fig. 3. Light-emitting diode (LED) signal transmittance signal as a function of time and three CCD photos of

365 fractionated wood powder sample taken after certain time periods. 


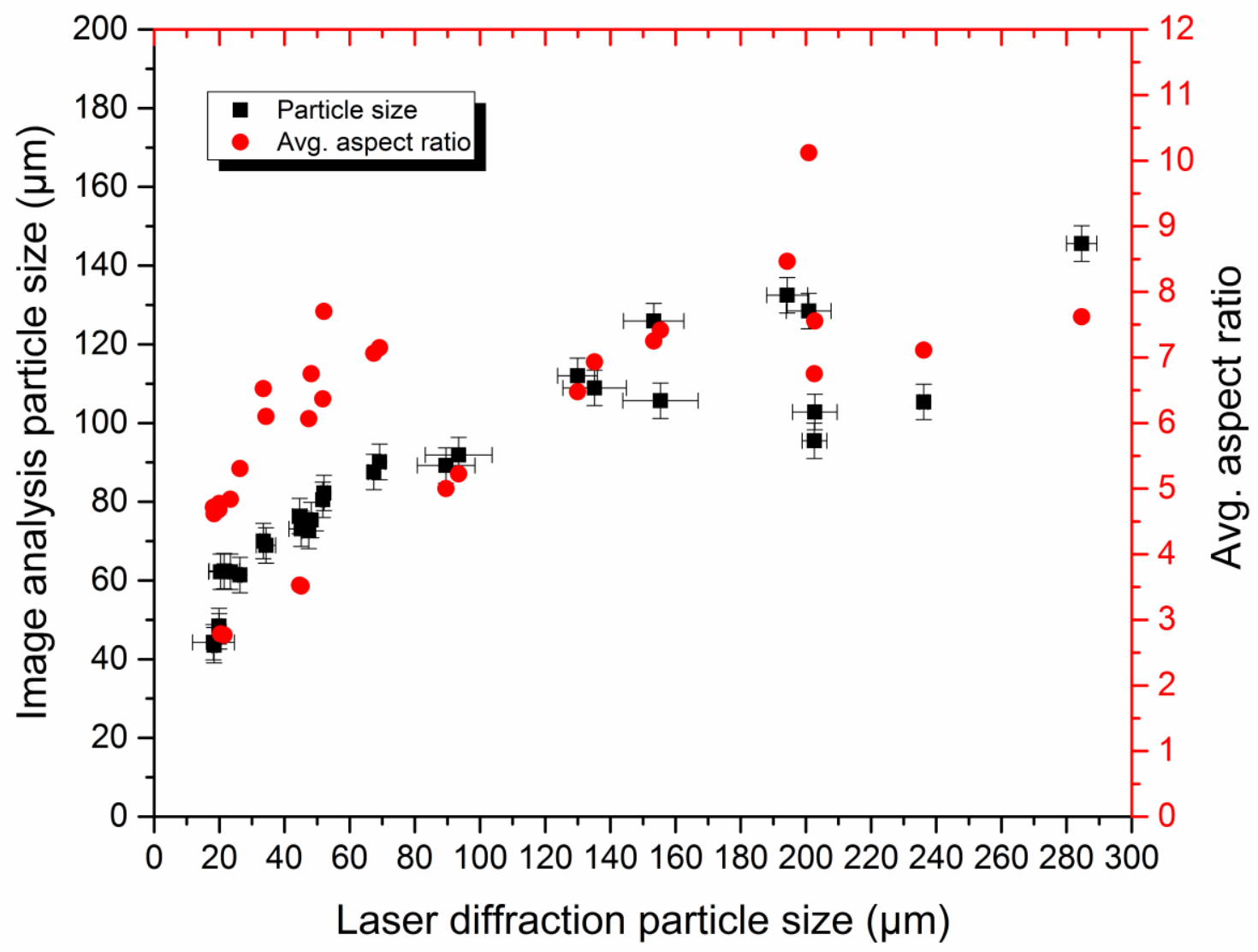

366

367 Fig. 4. Particle sizes of various wood samples analysed with tube flow fractionation method (based on image analysis) 368 and laser diffraction method (based on optical scattering) including standard deviation of both methods. Average aspect 369 ratio results based on image analysis.

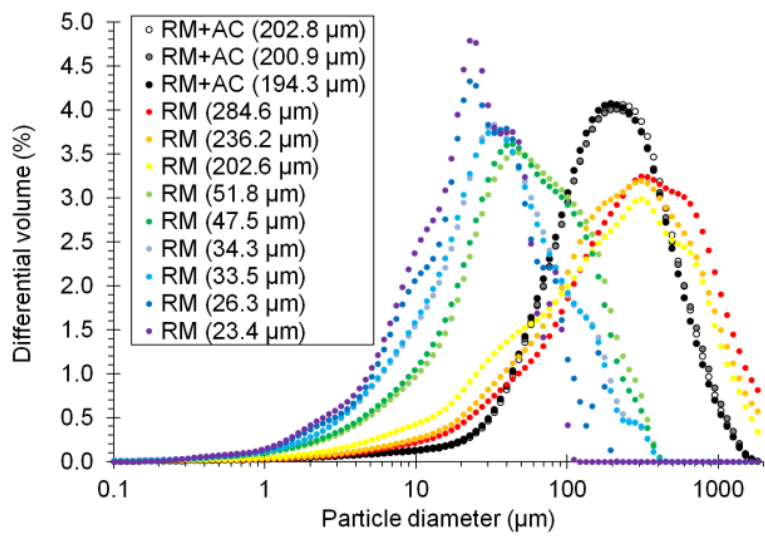

371 Fig. 5. Volumetric differential particle size distributions of rotor impact milled powders. 


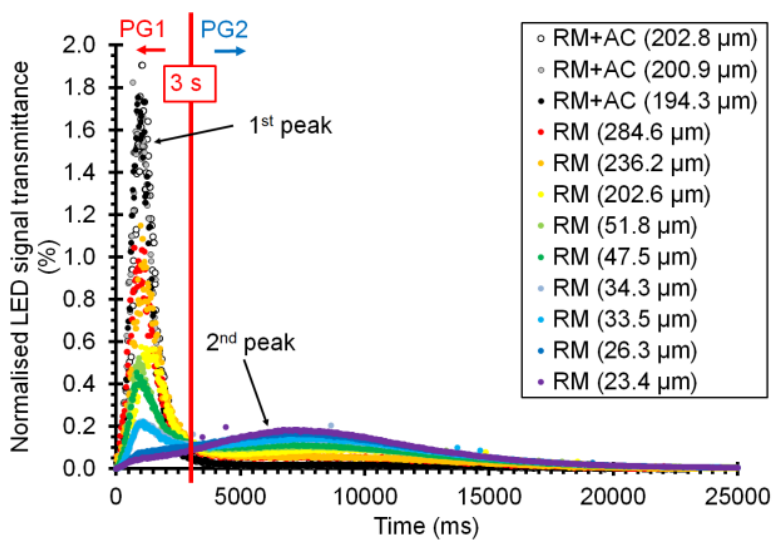

373 Fig. 6. Normalised LED signal transmittance curves as a function of time for fractionated rotor impact milled wood 374 powder samples. In the figure, PG1 stands for particle group 1, which flows before 3 s, and PG2 for particle group 2, 375 which flows after $3 \mathrm{~s}$.
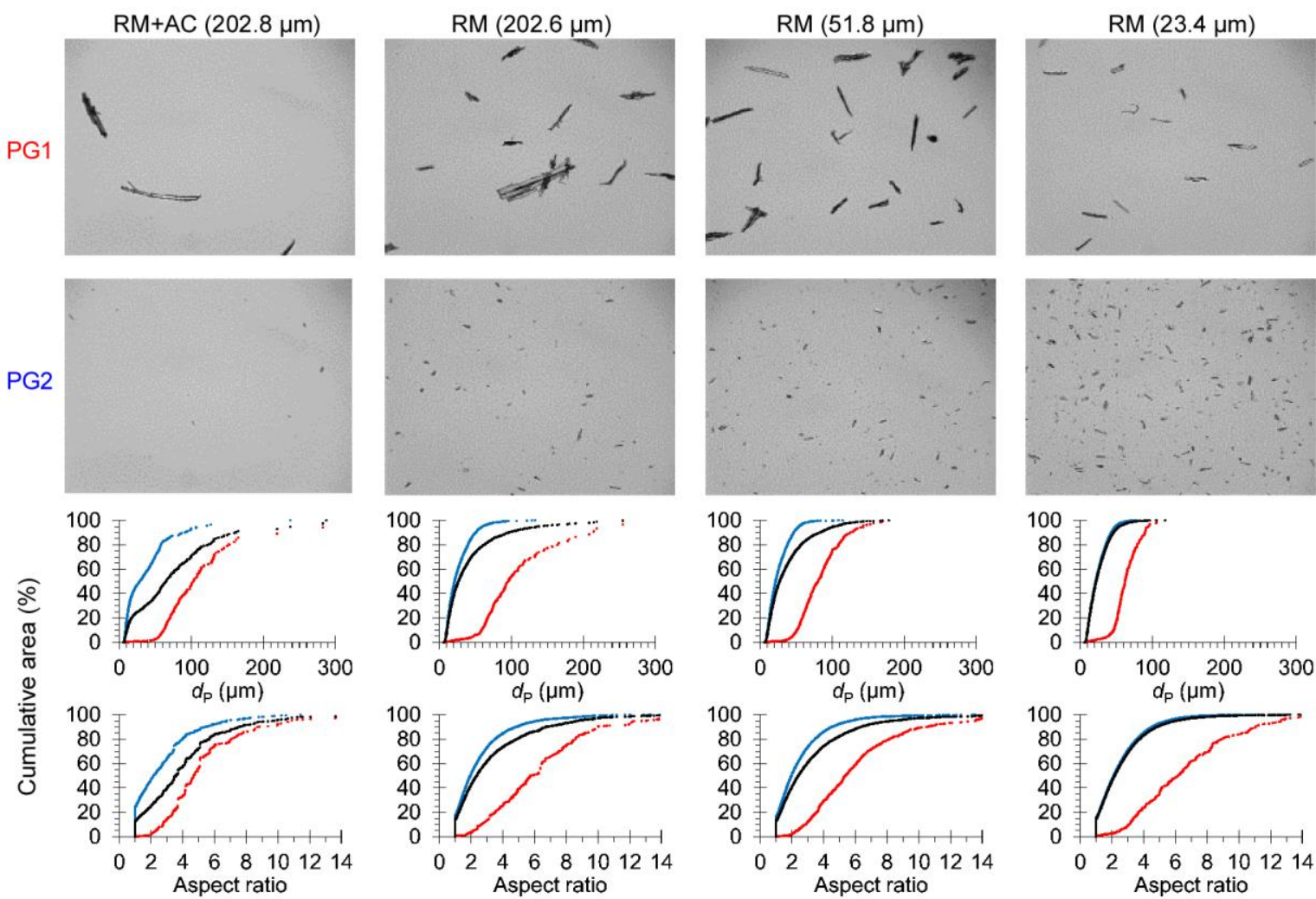

377 Fig. 7. CCD photos and cumulative area distributions of fractionated rotor impact milled wood powder samples. The

378 cumulative area distribution which considers only PG1 (see Fig. 5) is marked with '•’; PG2 (see Fig. 5) is marked with 379 '•’, and the whole sample is marked with ' $\bullet$ '. 


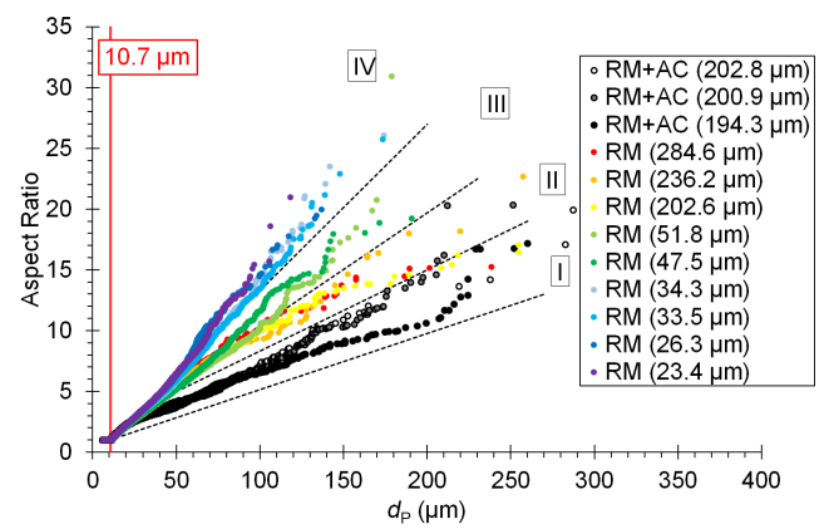

381 Fig. 8. Aspect ratio as a function of projected area diameter $d_{\mathrm{P}}$ for rotor impact milled wood powder samples. Black

382 dashed lines divide samples into groups I-IV.
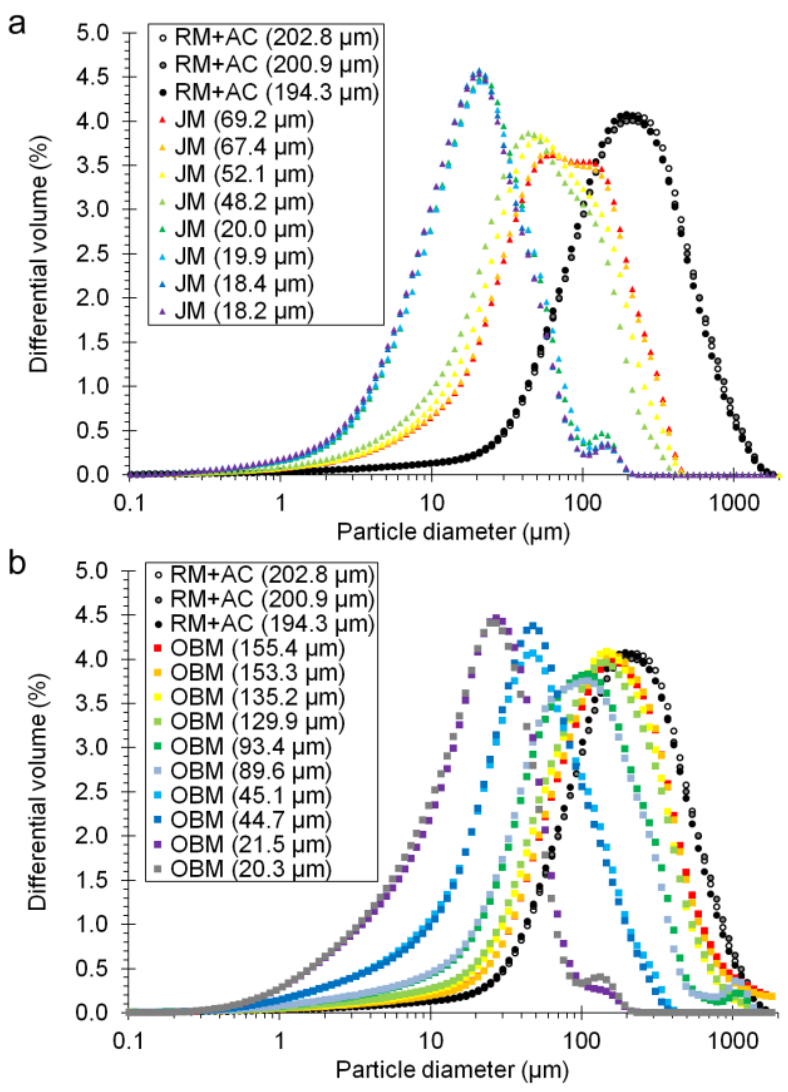

384 Fig. 9. Volumetric differential particle size distributions of a) jet milled (JM) and b) oscillatory ball milled (OBM) wood samples, where in both, $\mathrm{RM}+\mathrm{AC}$ has been used as the feed material. 

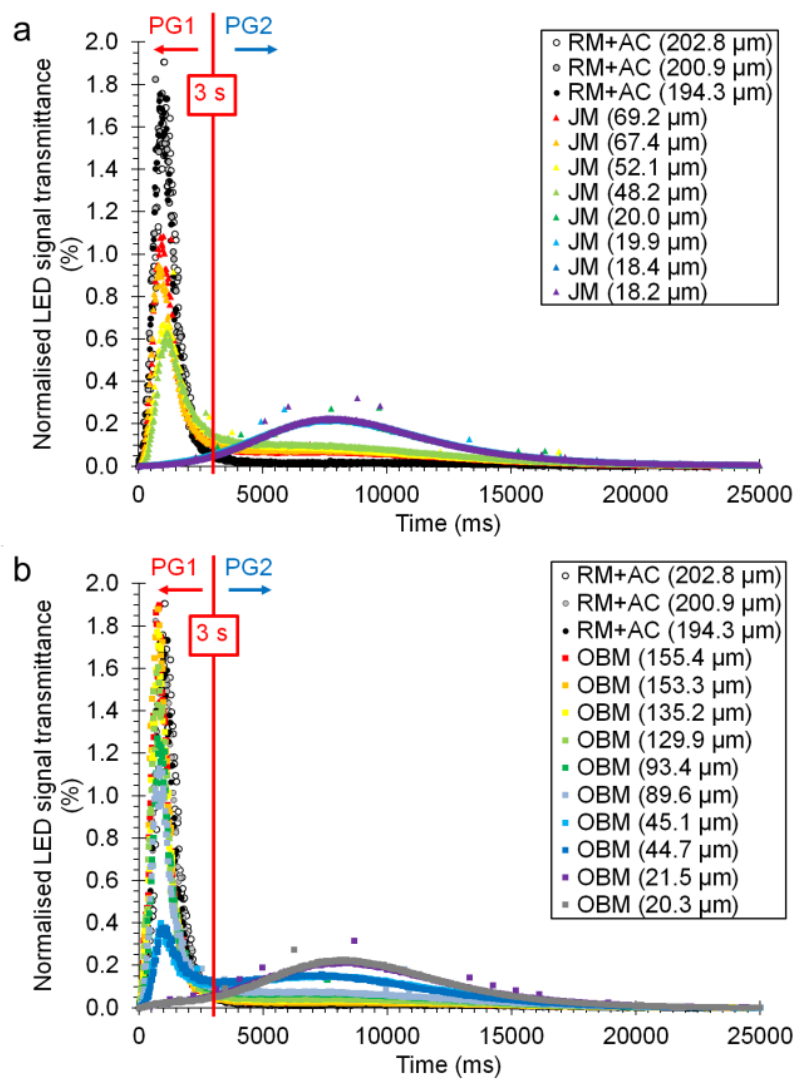

387 Fig. 10. Normalised LED signal transmittance curves as a function of time for fractionated a) jet milled (JM) and b)

388 oscillatory ball milled (OBM) wood samples where, in both, $\mathrm{RM}+\mathrm{AC}$ has been used as the feed material. 

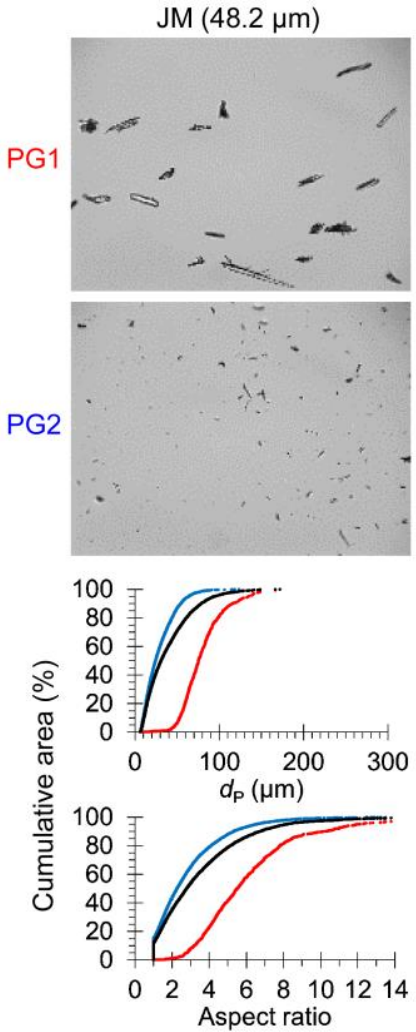
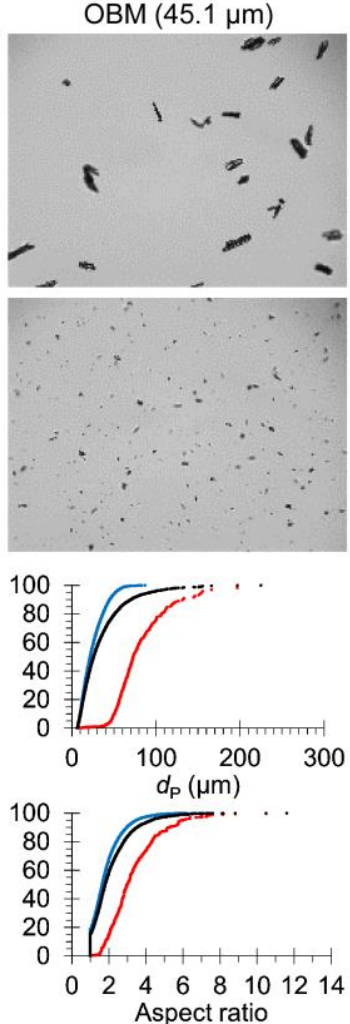
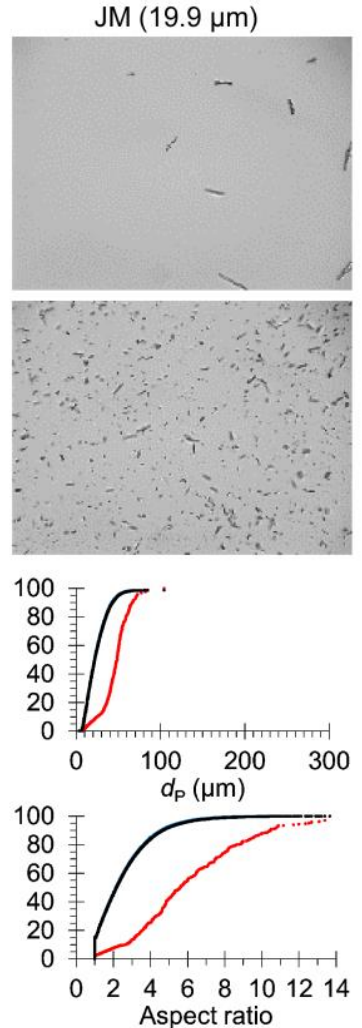
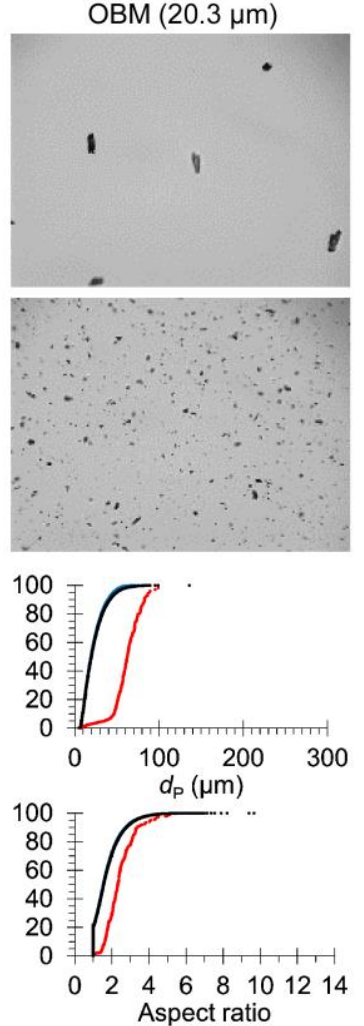

390 Fig. 11. CCD photos and cumulative area distributions of fractionated jet milled and oscillatory ball milled wood

391 powder samples. Cumulative area distribution that considers only the PG1 (see Fig. 9) is marked with '•’, PG2 (see Fig.

9) is marked with '•' and the whole sample is marked with '•’. 

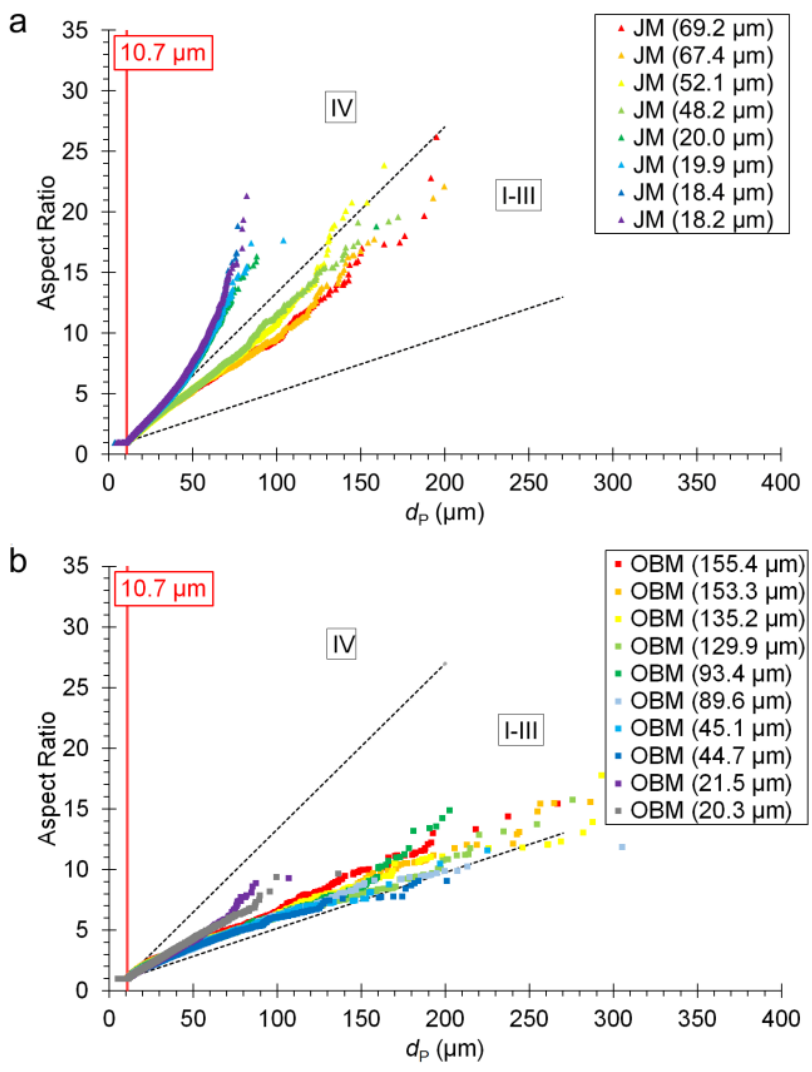

394 Fig. 12. Aspect ratio as a function of projected area diameters for a) jet milled and b) oscillatory ball milled wood 395 powder samples. Black dashed lines divide samples into groups I-IV, which are same as in Fig. 7. 

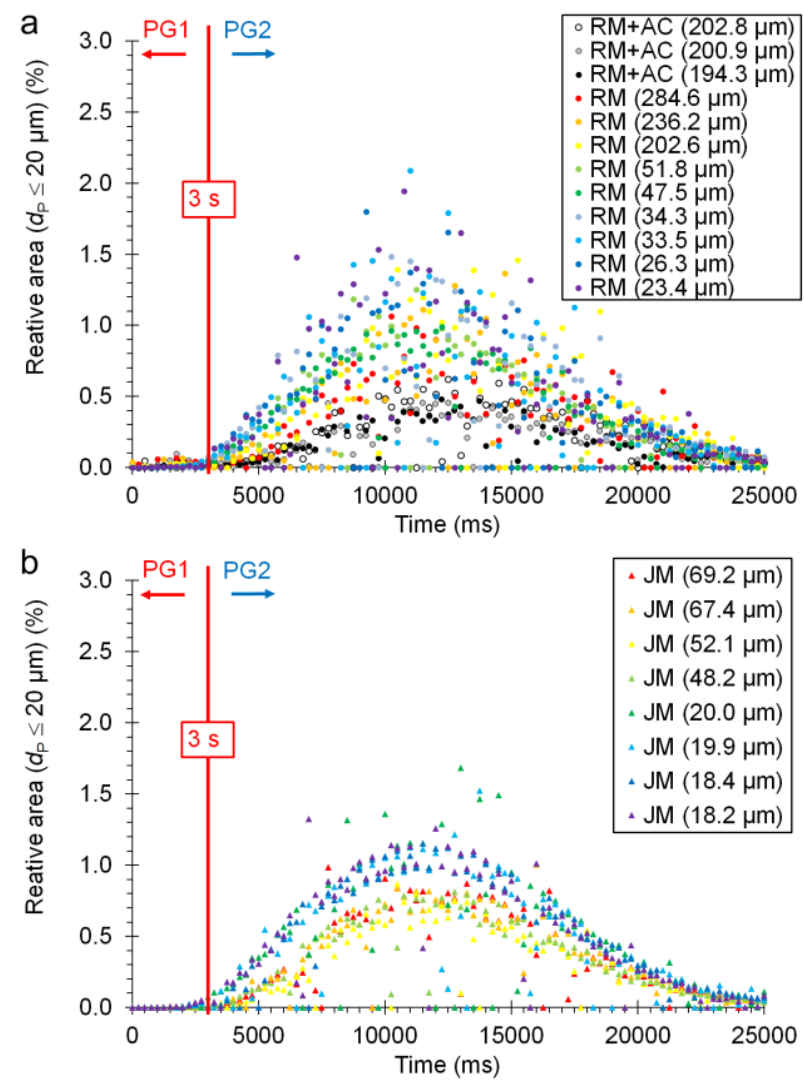

396

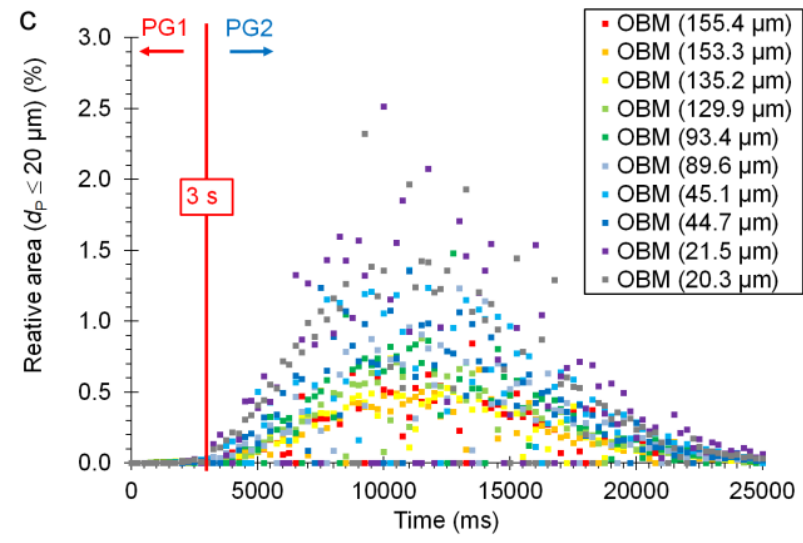

397 Fig. 13. Relative area of the particles having $d_{\mathrm{P}} \leq 20 \mu \mathrm{m}$ as a function of time after fractionation. 


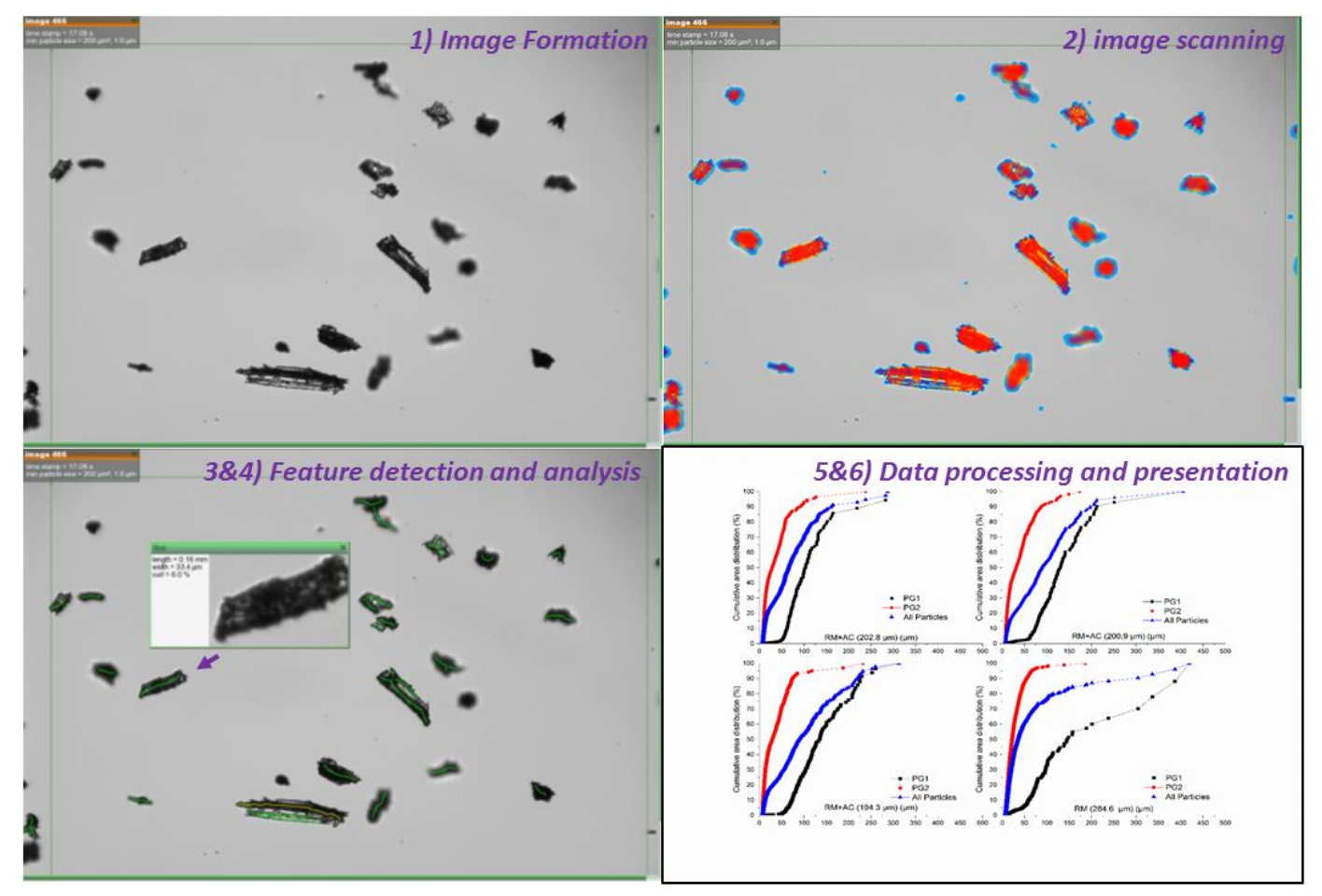

399 Fig. A.1. Schematic description of the image analysis procedure. 

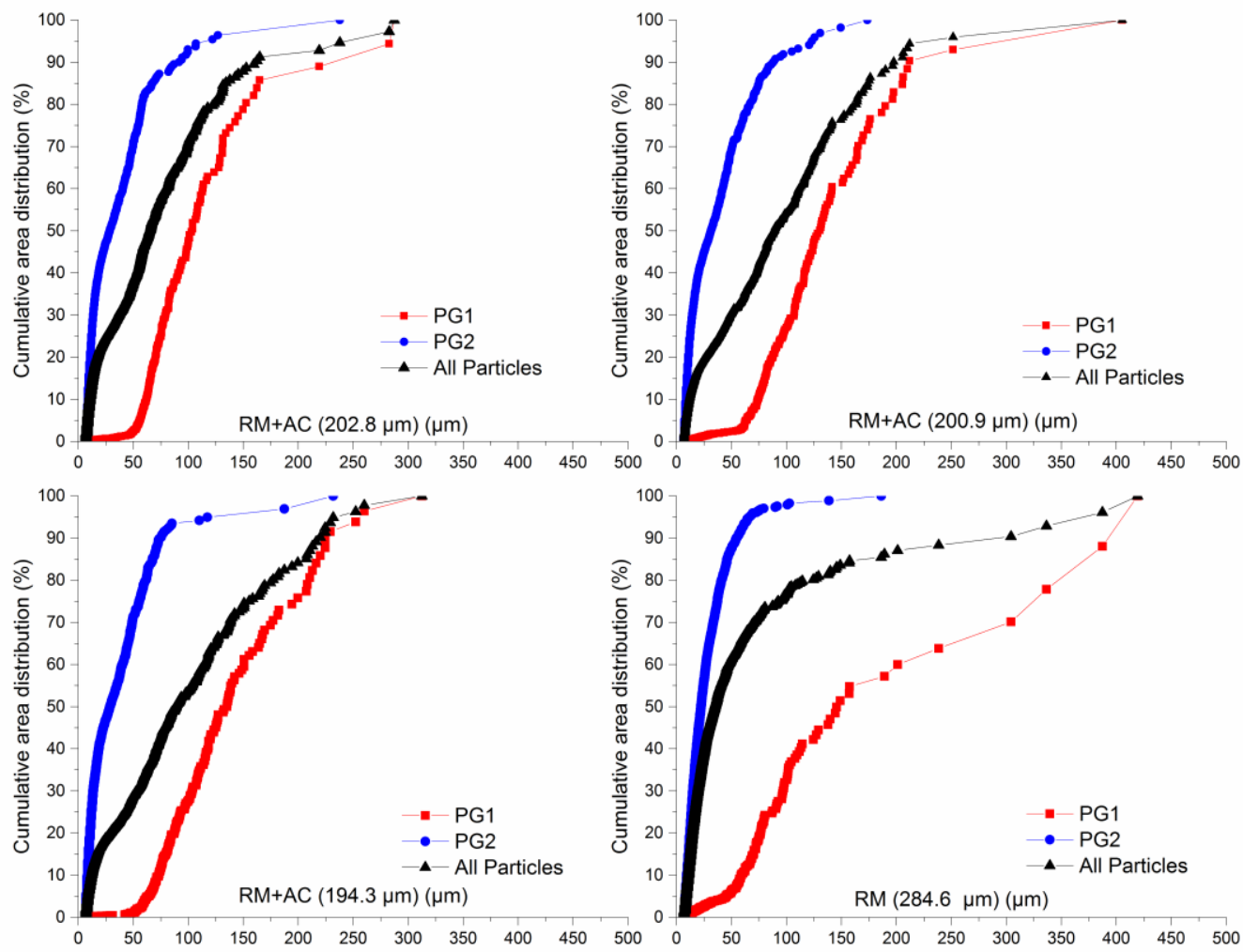

401 Fig. B.1. Cumulative area distributions of different RM+AC and RM samples as a function of $d_{\mathrm{P}}$. Particle group 1 is marked with ' $\square$ ', particle group 2 is marked with ' $\bullet$ ' and the whole sample is marked with ' $\boldsymbol{\Delta}$ '. 

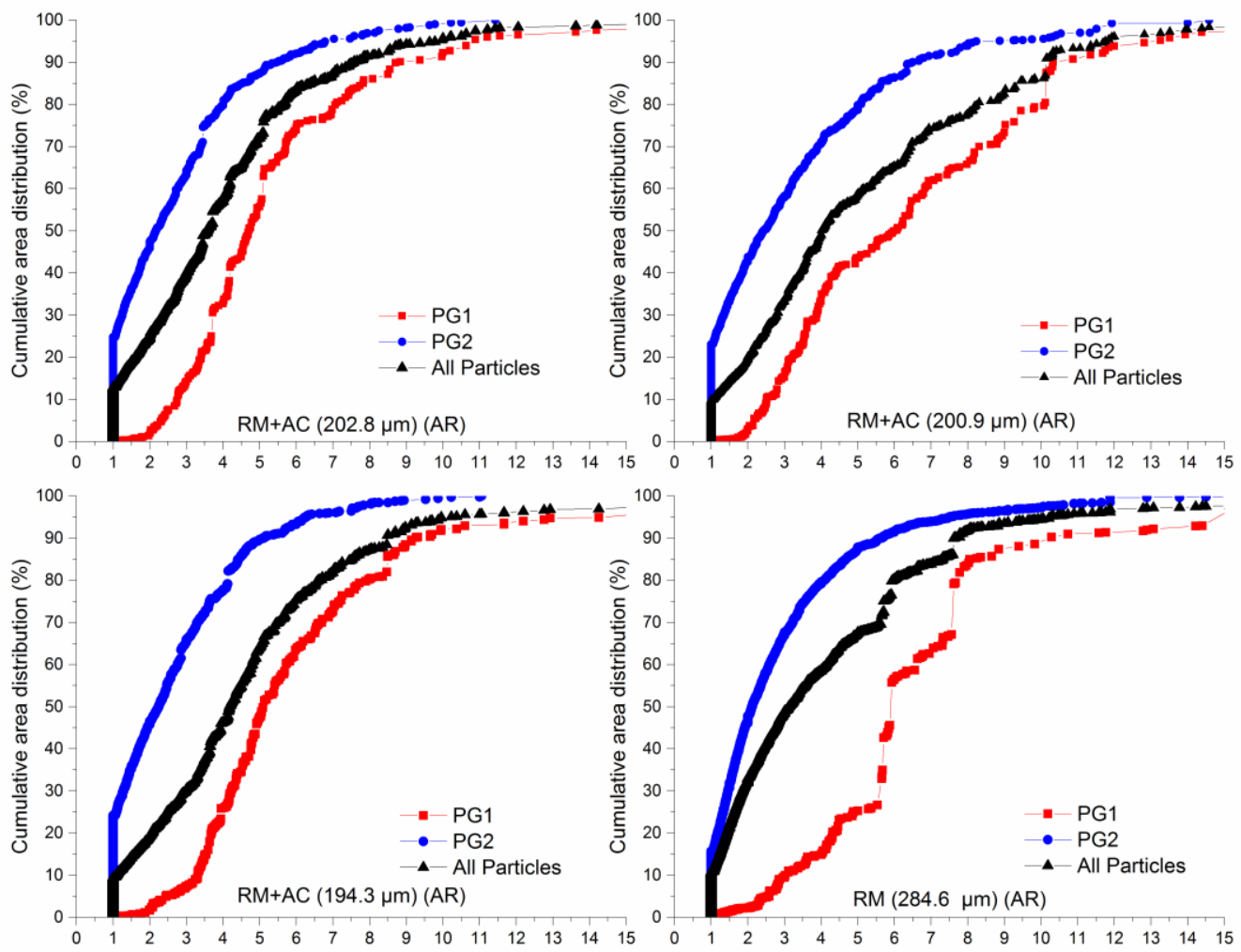

404 Fig. B.2. Cumulative area distributions of different RM+AC and RM samples as a function of AR. Particle group 1 is marked with ' $\square$ ', particle group 2 is marked with ' $\bullet$ ' and the whole sample is marked with ' $\boldsymbol{\Delta}$ '. 

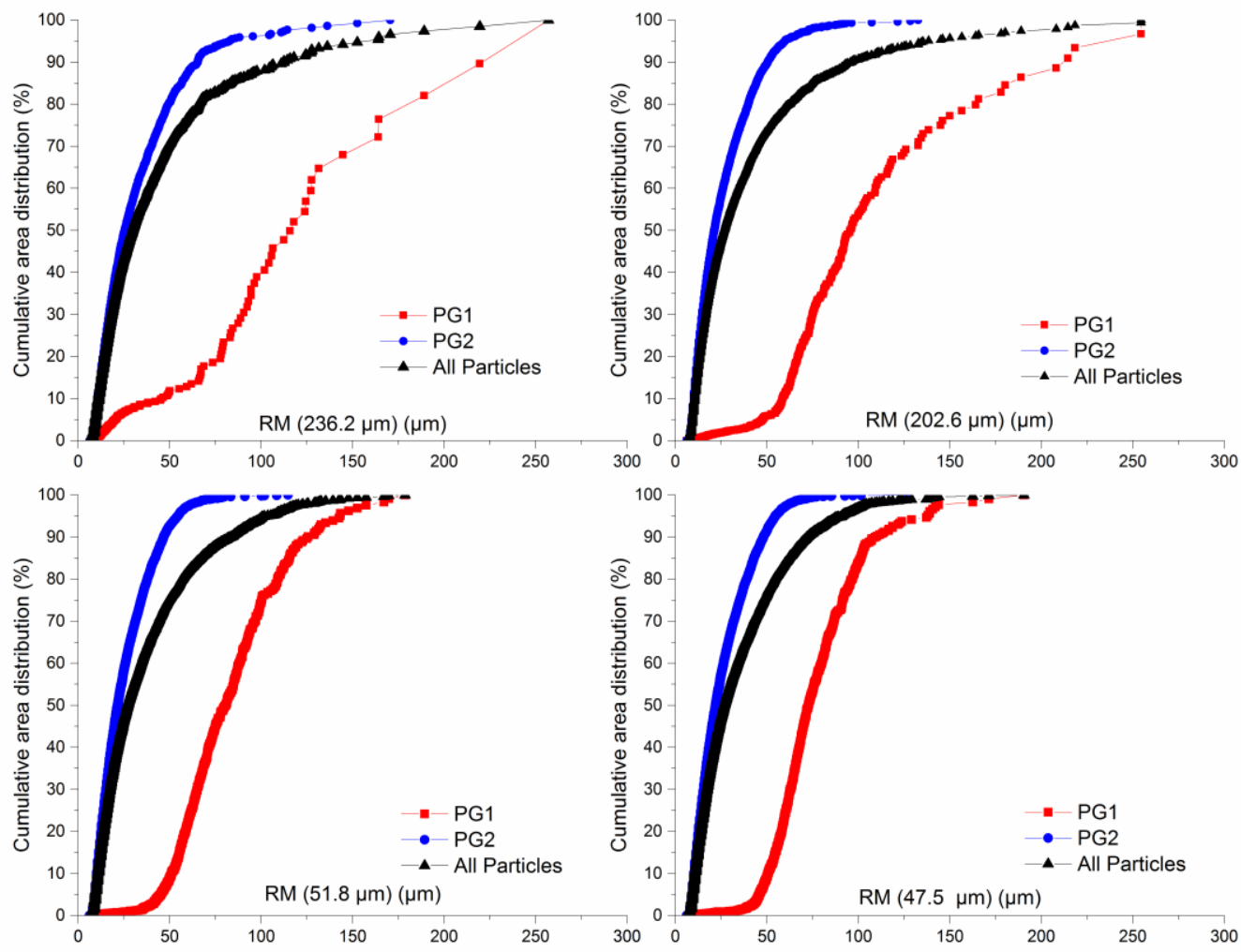

407 Fig. B.3. Cumulative area distributions of different RM samples as a function of $d_{\mathrm{P}}$. Particle group 1 is marked with ' $\square$ ', 408 particle group 2 is marked with ' $\bullet$ ' and the whole sample is marked with ' $\boldsymbol{\Lambda}$ '. 

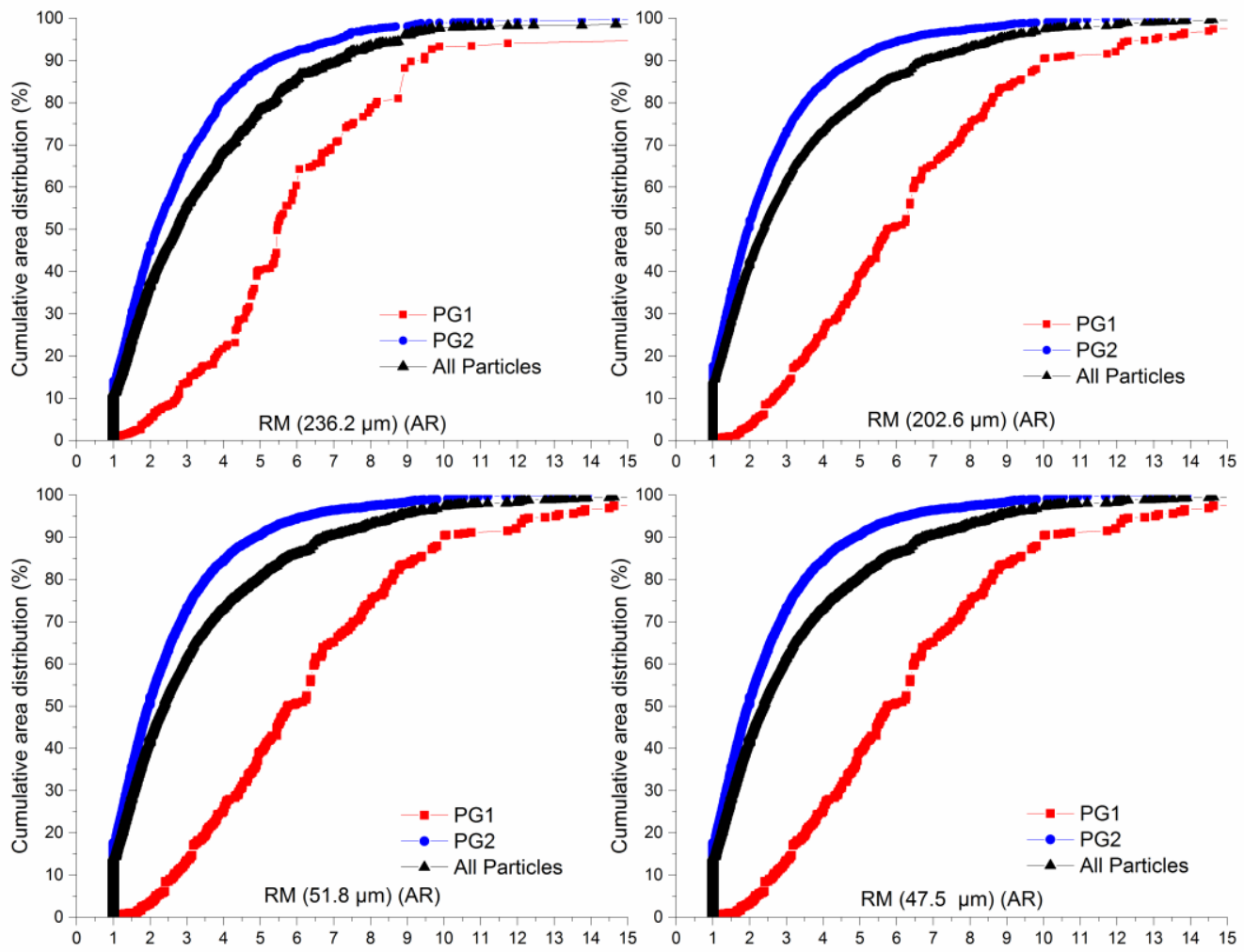

410 Fig. B.4. Cumulative area distributions of different RM samples as a function of AR. Particle group 1 is marked with 411 ' $\square$ ', particle group 2 is marked with ' $\bullet$ ' and the whole sample is marked with ' $\mathbf{\Delta}$ '. 

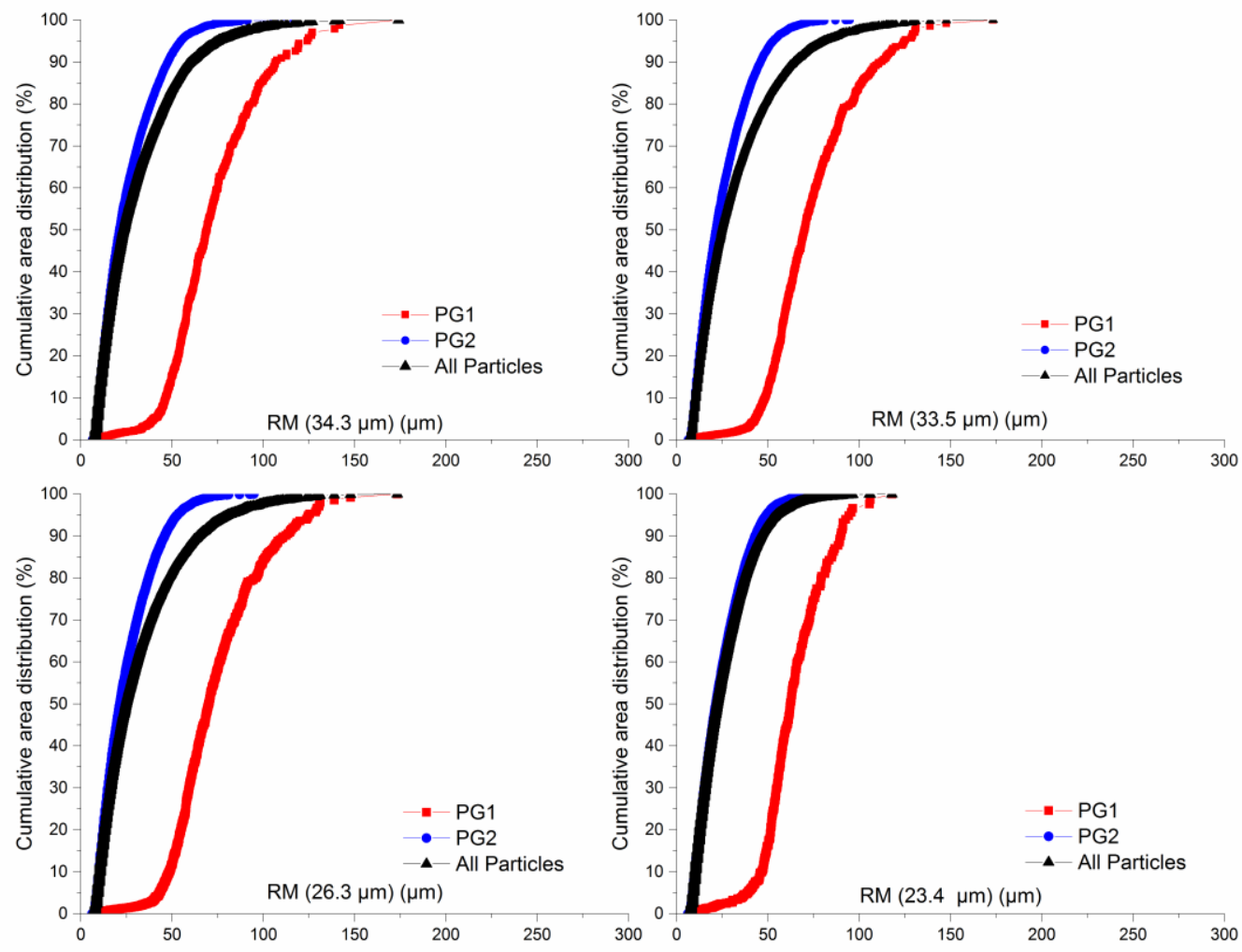

412

413 Fig. B.5. Cumulative area distributions of different RM samples as a function of $d_{\mathrm{P}}$. Particle group 1 is marked with ' $\square$ ', 414 particle group 2 is marked with ' $\bullet$ ' and the whole sample is marked with ' $\Delta$ '. 


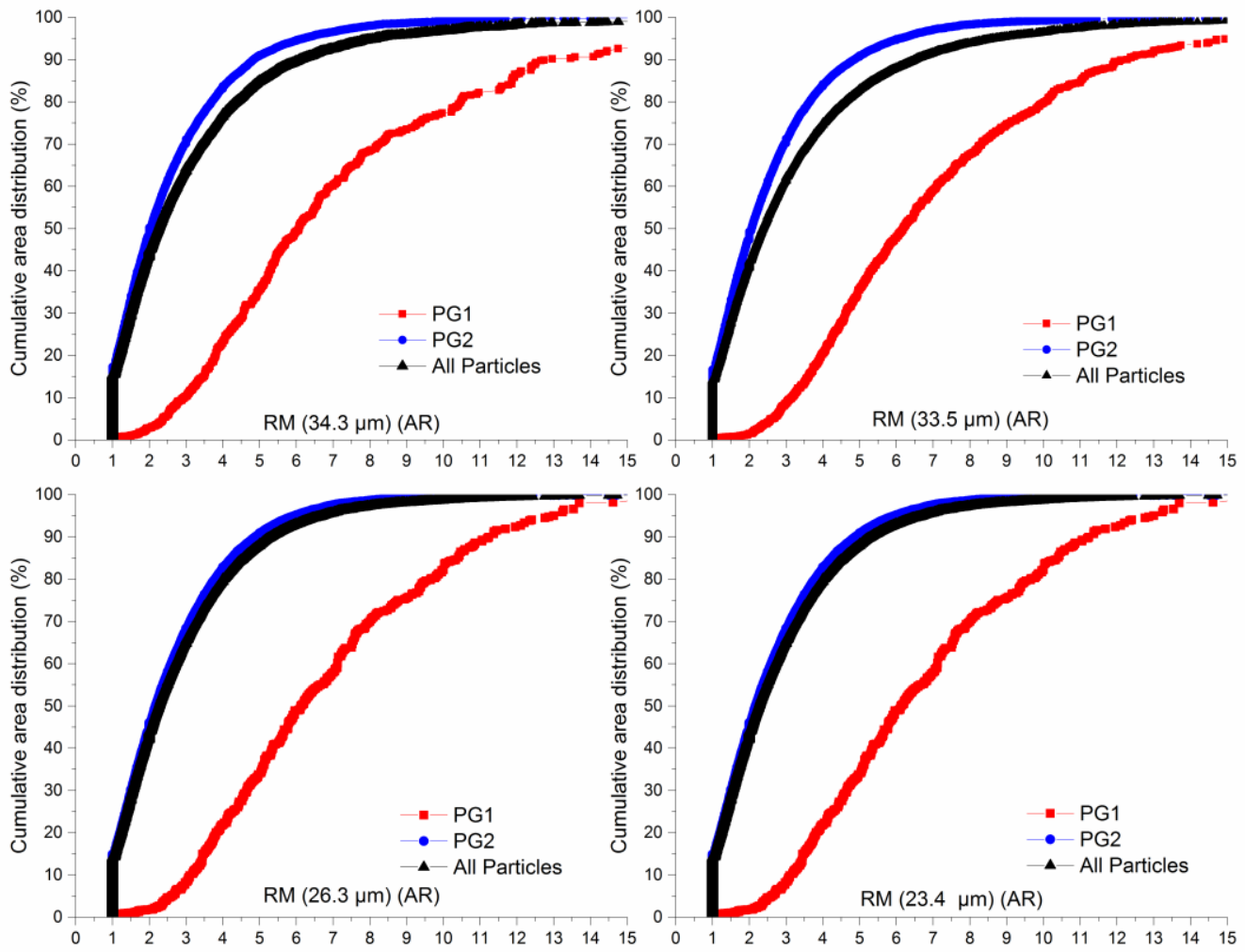

415

416 Fig. B.6. Cumulative area distributions of different RM samples as a function of AR. Particle group 1 is marked with 417 ' $\square$ ', particle group 2 is marked with ' $\bullet$ ' and the whole sample is marked with ' $\boldsymbol{\Delta}$ '. 

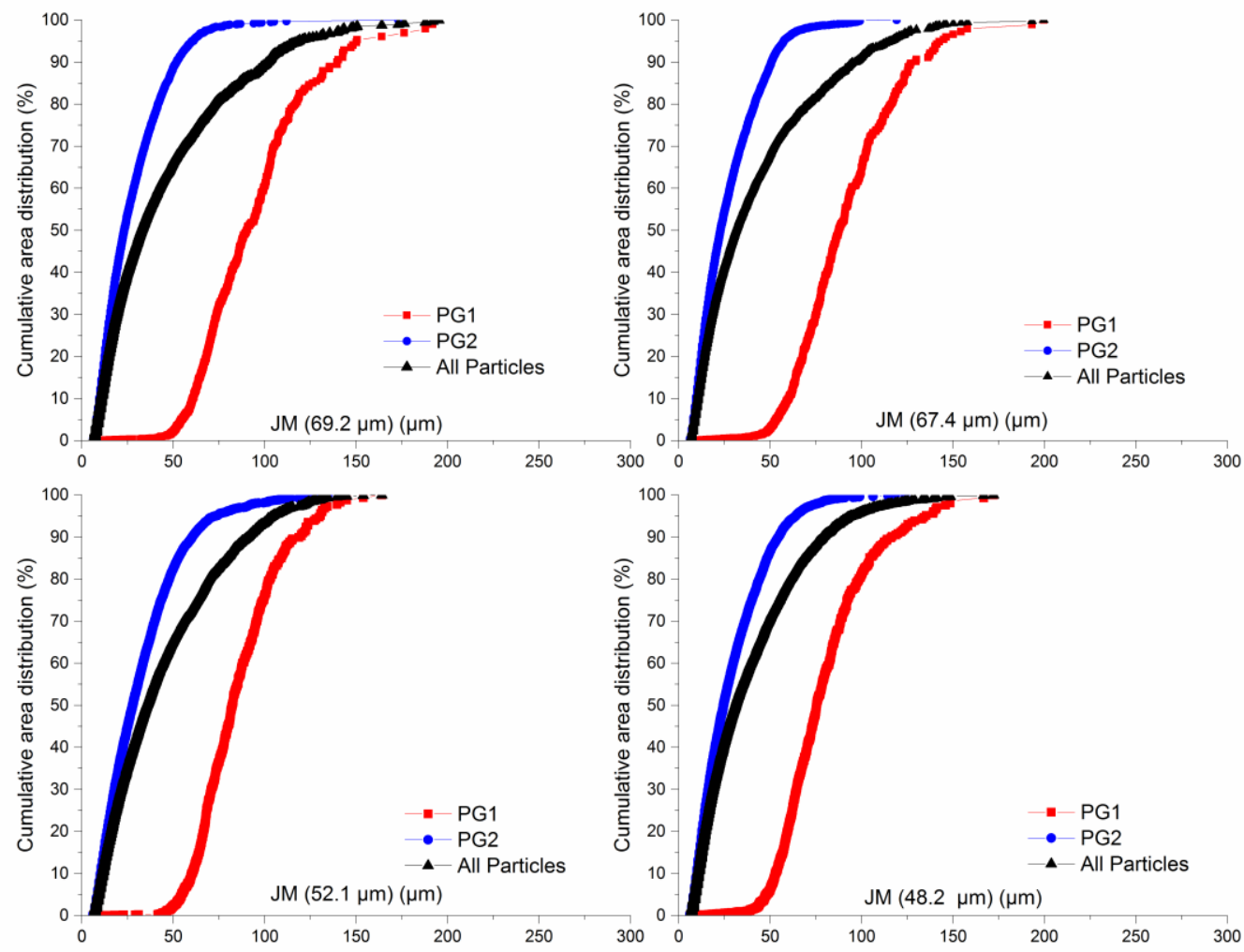

419 Fig. B.7. Cumulative area distributions of different JM samples as a function of $d_{\mathrm{P}}$. Particle group 1 is marked with ' $\square$ ', particle group 2 is marked with ' $\bullet$ ' and the whole sample is marked with ' $\boldsymbol{\Delta}$ '. 

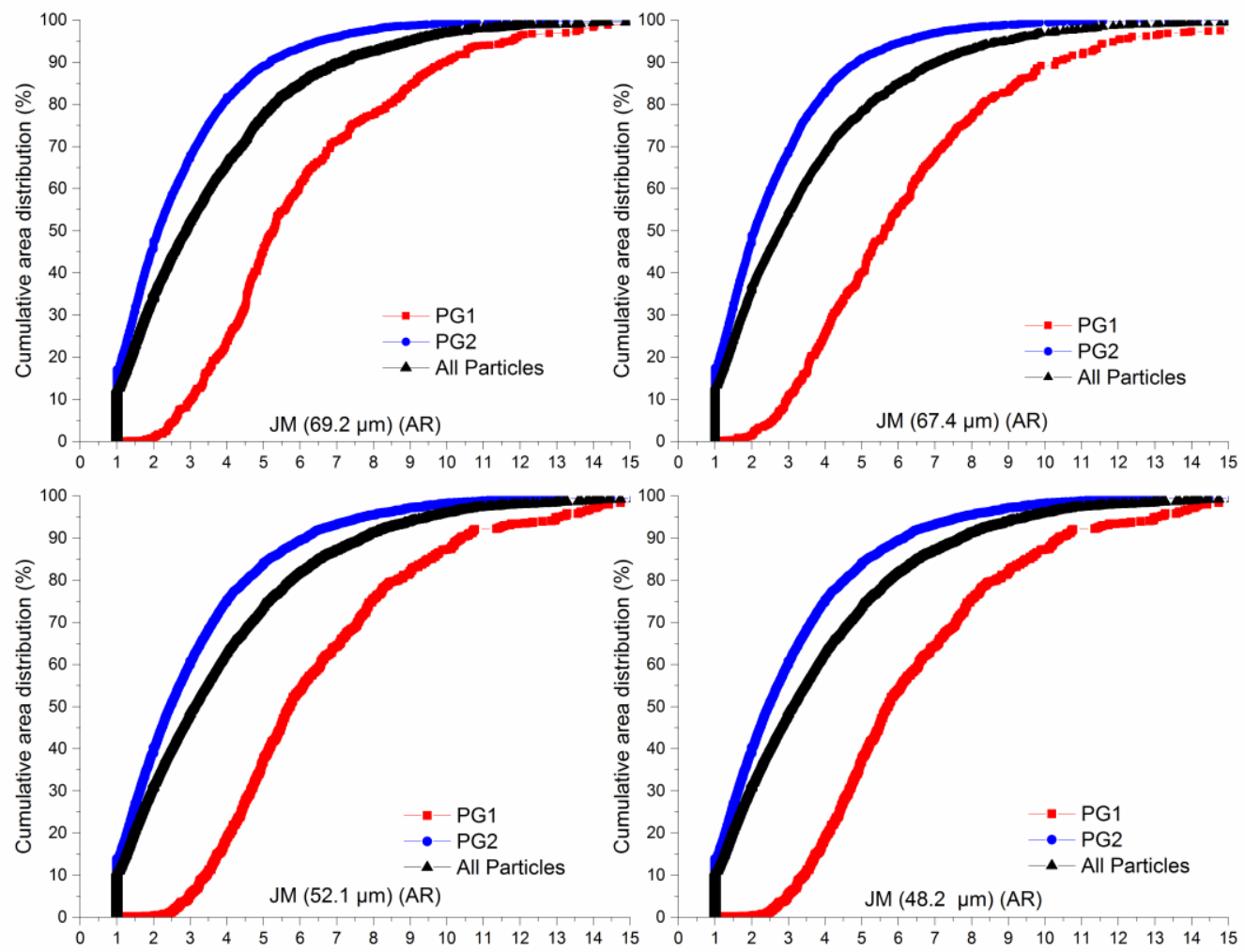

422 Fig. B.8. Cumulative area distributions of different JM samples as a function of AR. Particle group 1 is marked with ' $\boldsymbol{\prime}$ ', particle group 2 is marked with ' $\bullet$ ' and the whole sample is marked with ' $\mathbf{\Delta}$ '. 

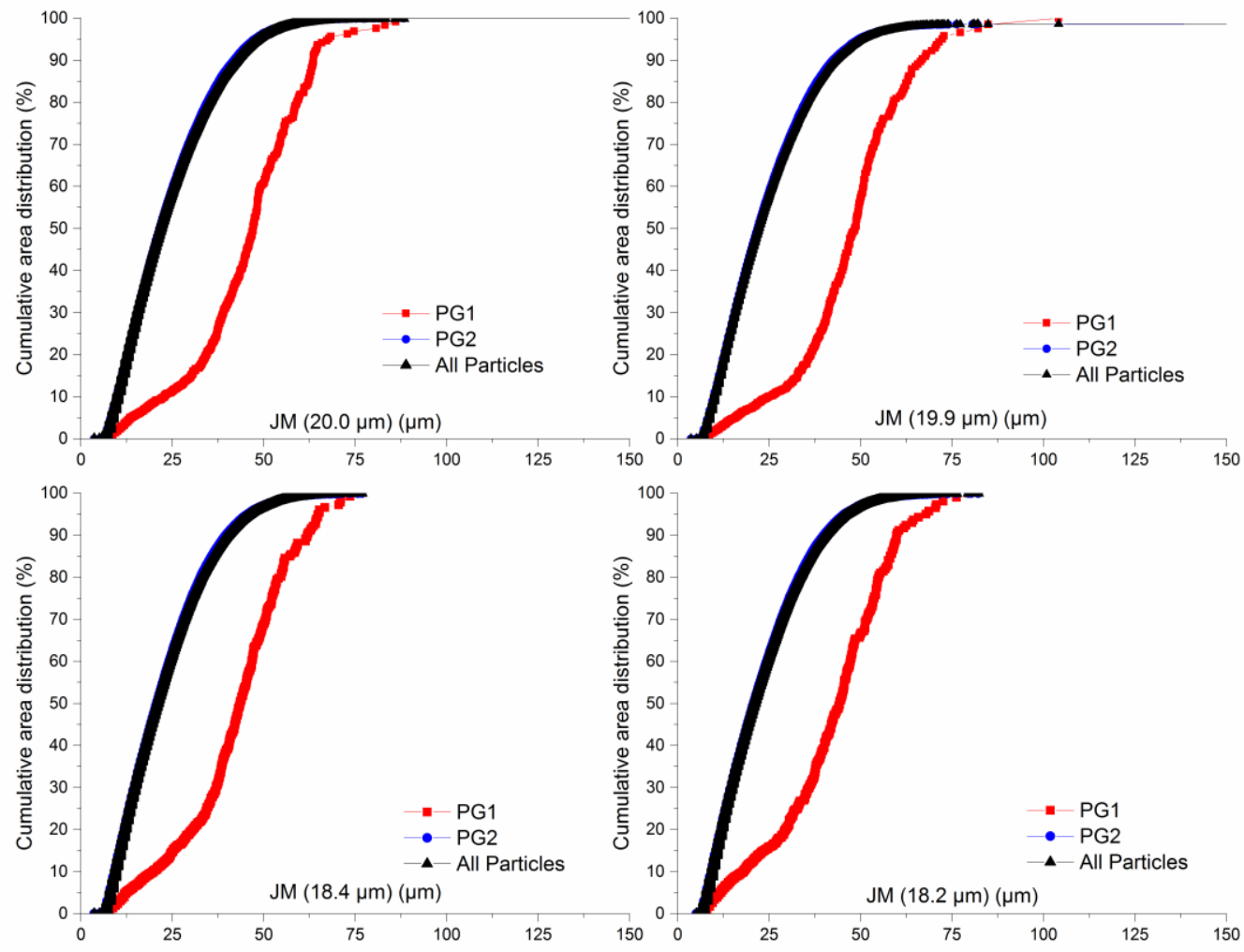

425 Fig. B.9. Cumulative area distributions of different JM samples as a function of $d_{\mathrm{P}}$. Particle group 1 is marked with ' $\square$ ', particle group 2 is marked with ' $\bullet$ ' and the whole sample is marked with ' $\boldsymbol{\Delta}$ '. 

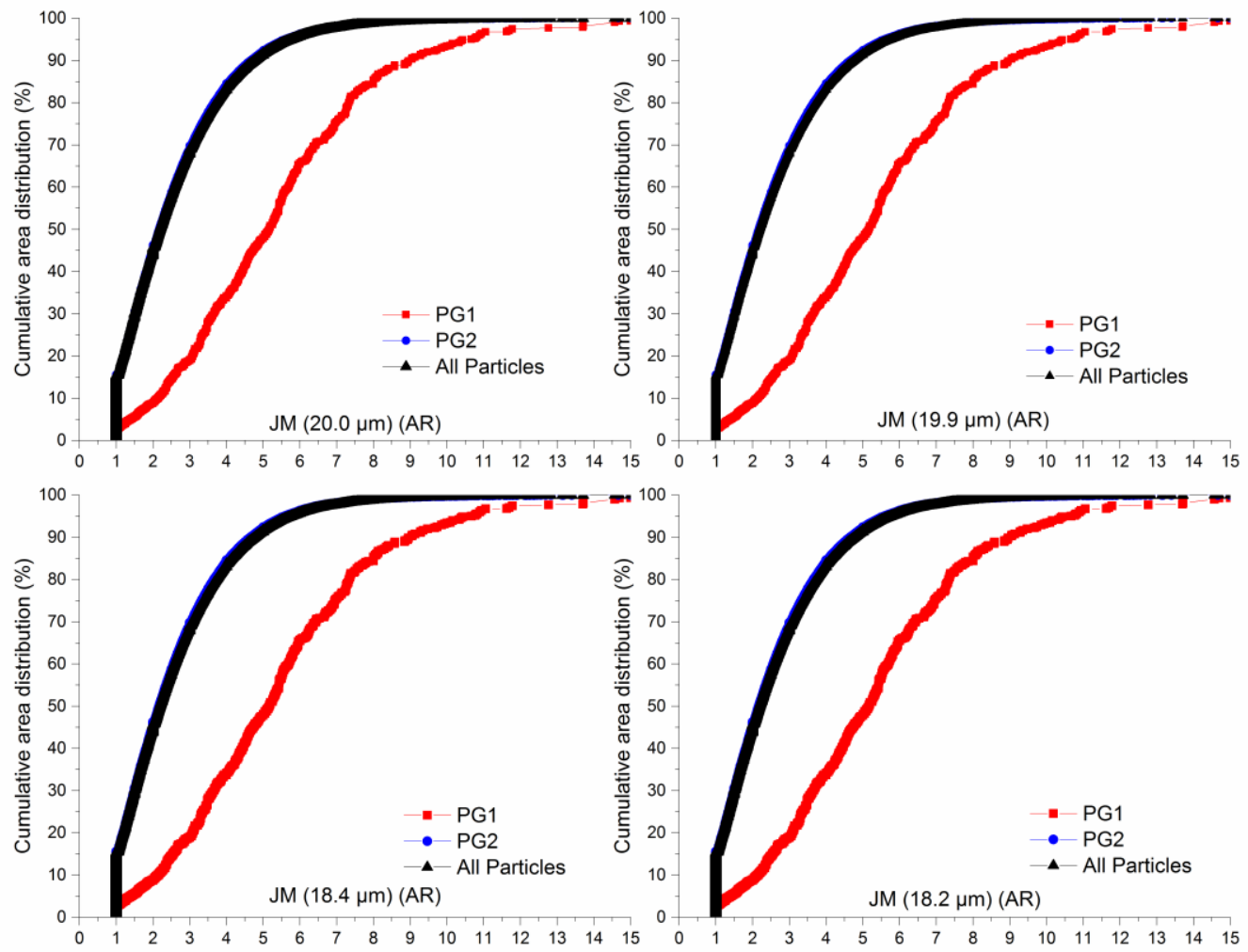

428 Fig. B.10. Cumulative area distributions of different JM samples as a function of AR. Particle group 1 is marked with ' $\square$ ', particle group 2 is marked with ' $\bullet$ ' and the whole sample is marked with ' $\boldsymbol{\Delta}$ '. 

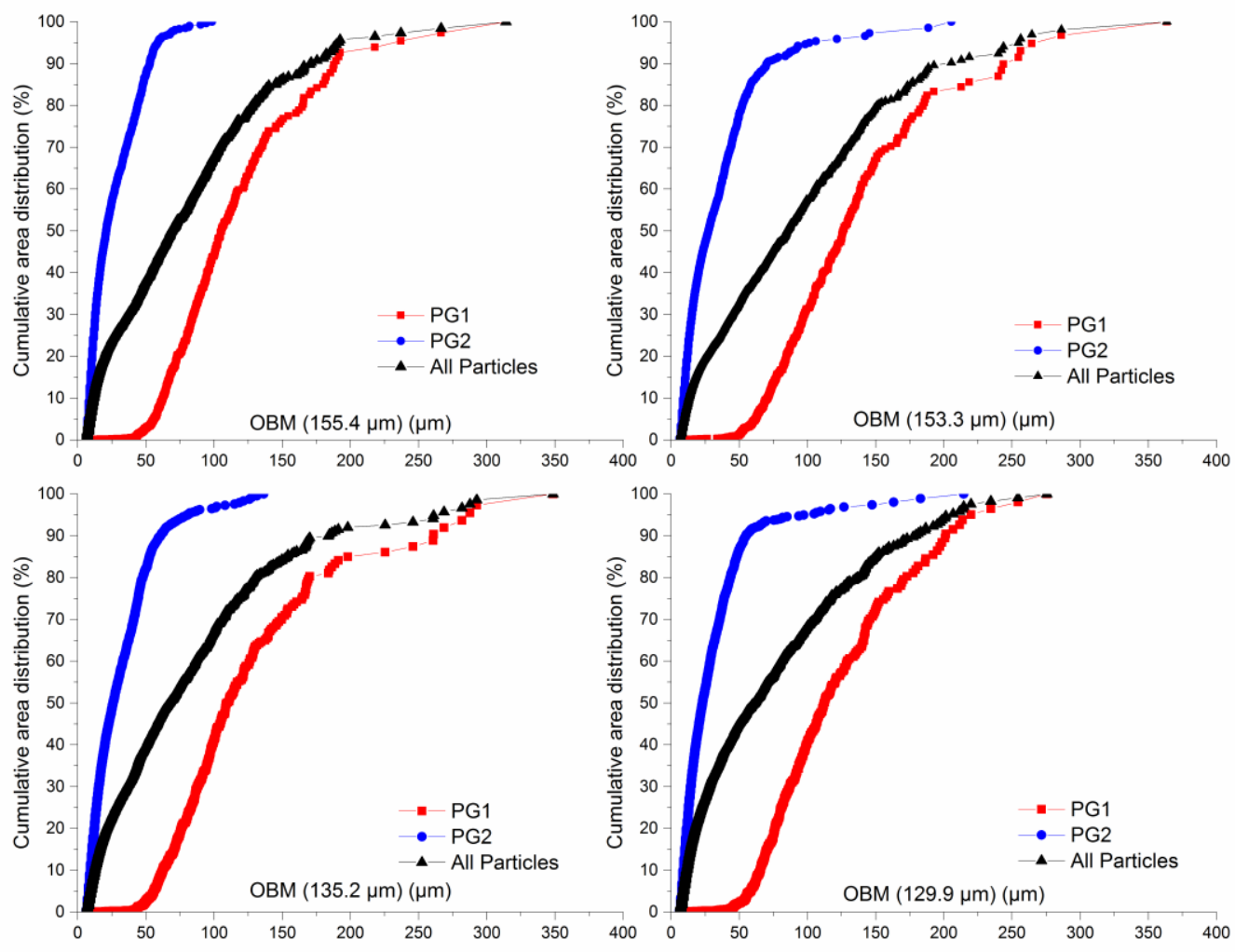

431 Fig. B.11. Cumulative area distributions of different OBM samples as a function of $d_{\mathrm{P}}$. Particle group 1 is marked with ' $\square$ ', particle group 2 is marked with ' $\bullet$ ' and the whole sample is marked with ' $\boldsymbol{\Delta}$ '. 

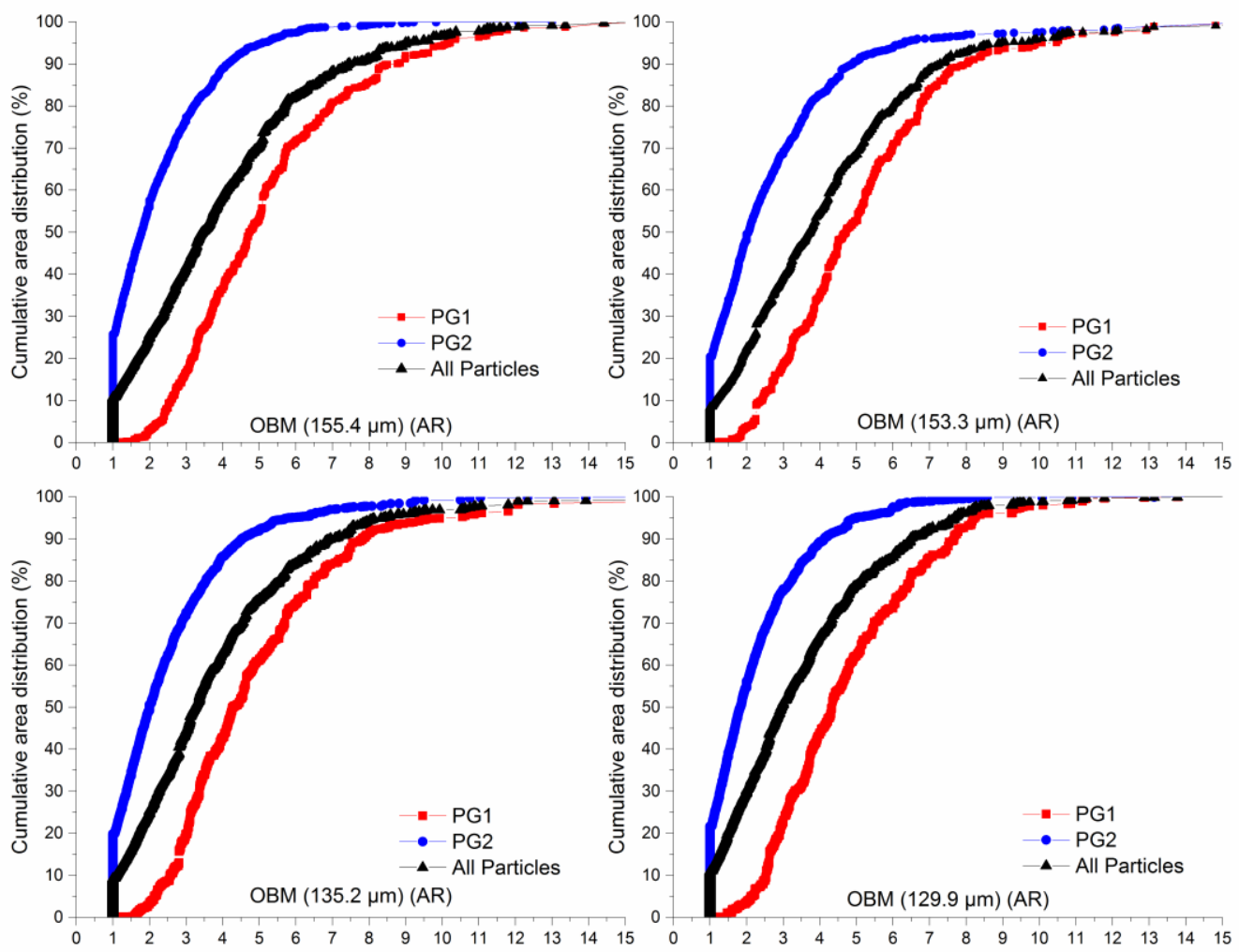

434 Fig. B.12. Cumulative area distributions of different OBM samples as a function of AR. Particle group 1 is marked with ' $\square$ ', particle group 2 is marked with ' $\bullet$ ' and the whole sample is marked with ' $\boldsymbol{\Delta}$ '. 

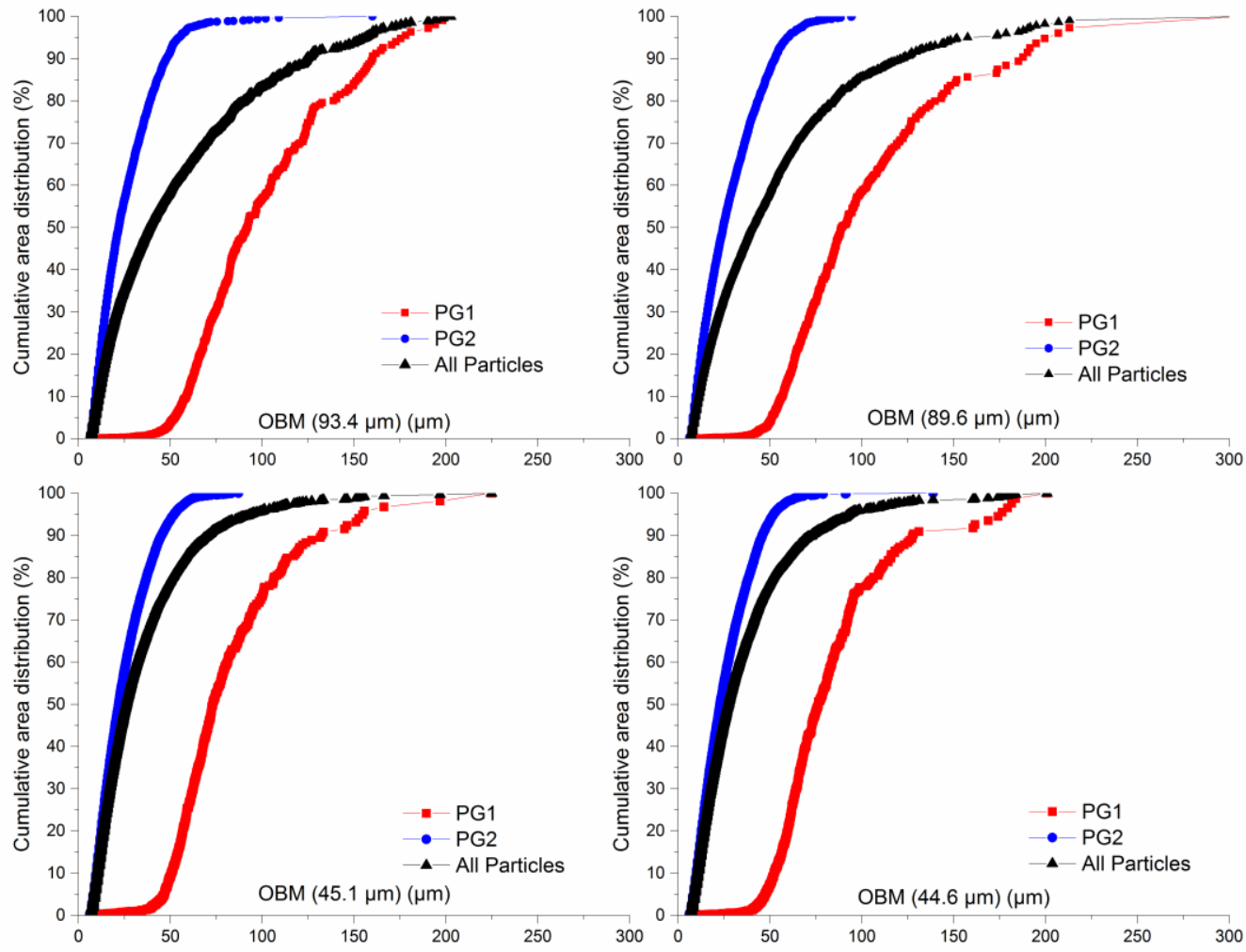

437 Fig. B.13. Cumulative area distributions of different OBM samples as a function of $d_{\mathrm{P}}$. Particle group 1 is marked with ' $\square$ ', particle group 2 is marked with ' $\bullet$ ' and the whole sample is marked with ' $\mathbf{\Delta}$ '. 

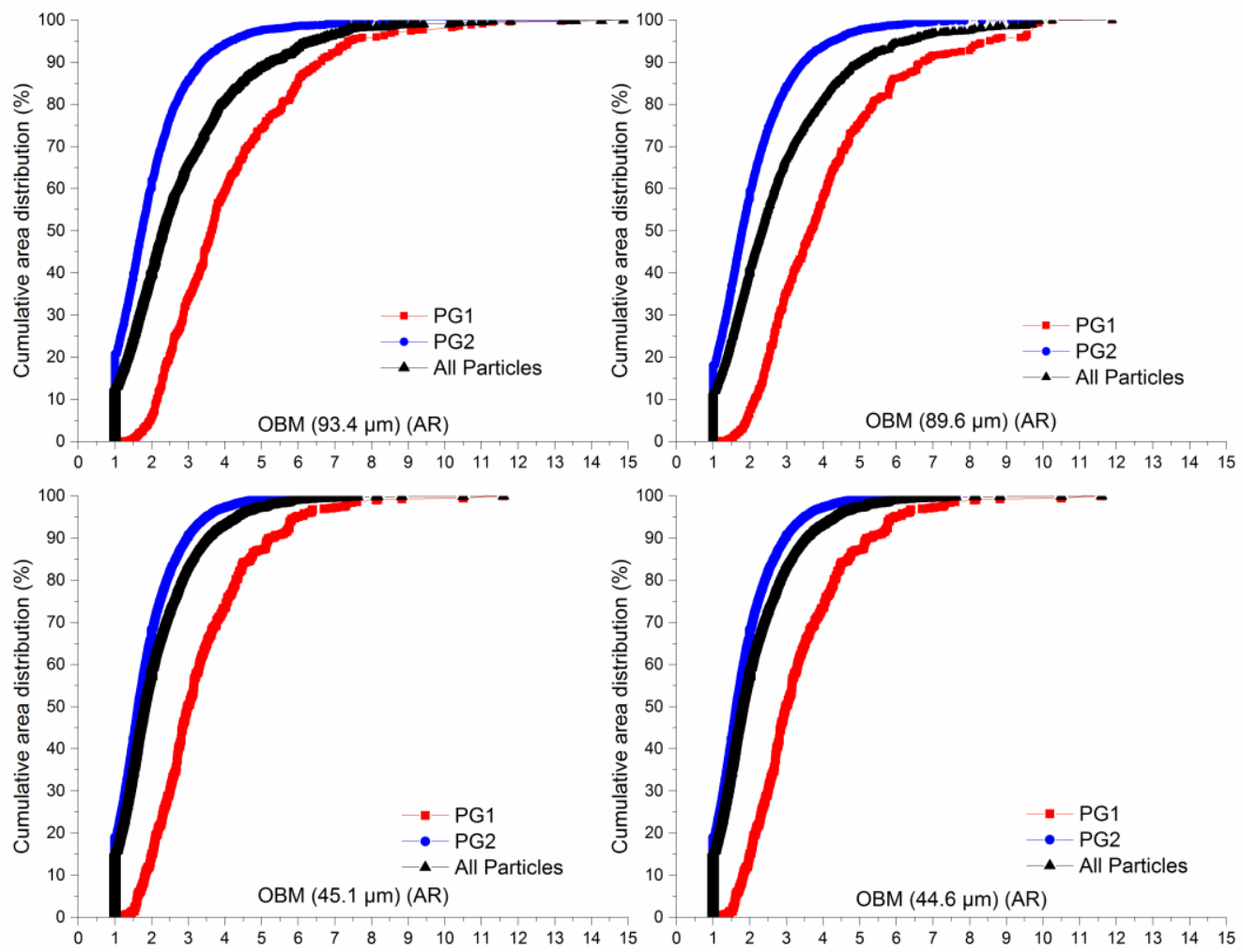

439

440 Fig. B.14. Cumulative area distributions of different OBM samples as a function of AR. Particle group 1 is marked with 441 ' $\square$ ', particle group 2 is marked with ' $\bullet$ ' and the whole sample is marked with ' $\boldsymbol{\Delta}$ '. 

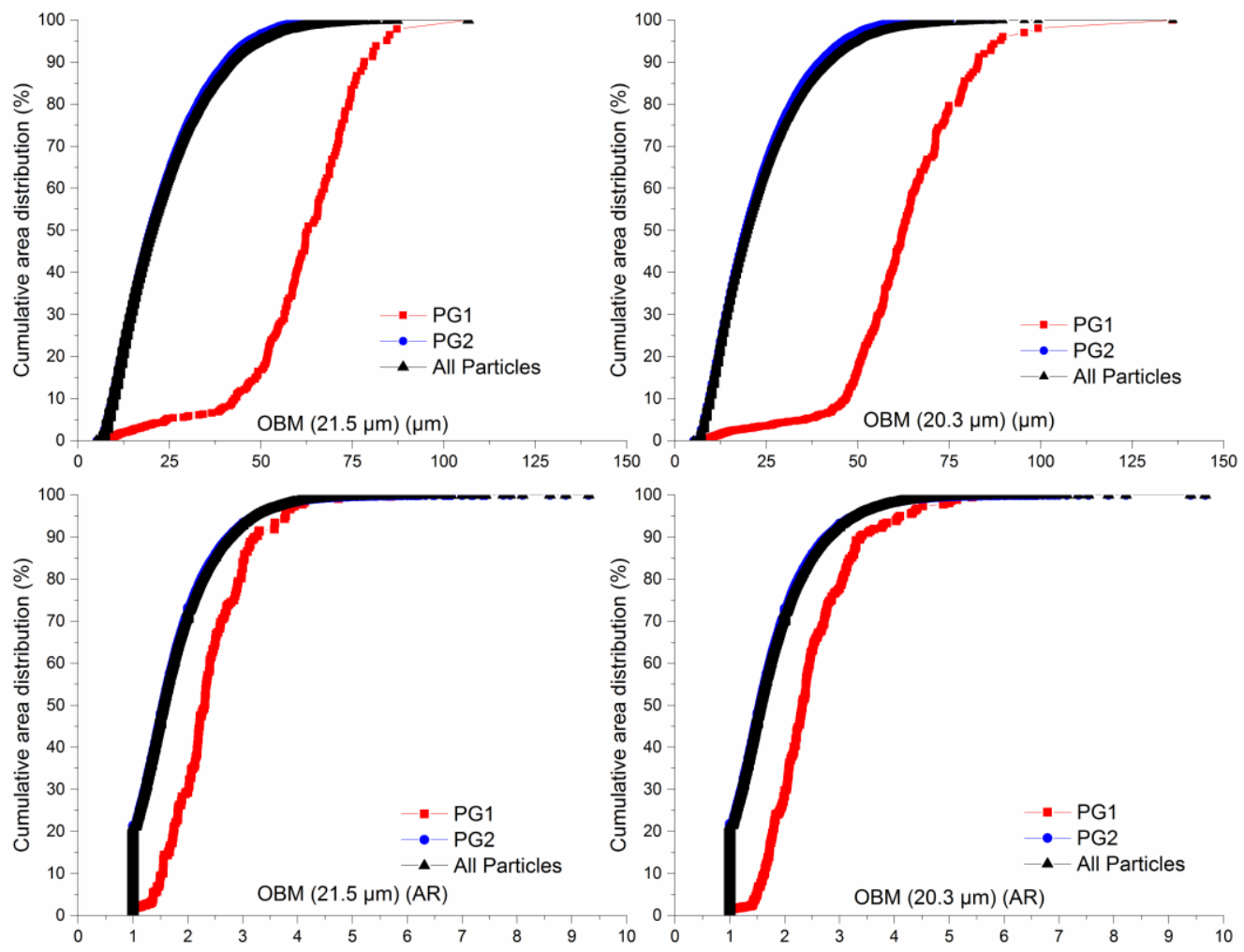

443 Fig. B.15. Cumulative area distributions of different OBM samples as a function of $d_{\mathrm{P}}$ and AR. Particle group 1 is 444 marked with ' $\square$ ', particle group 2 is marked with ' $\bullet$ ' and the whole sample is marked with ' $\boldsymbol{\Delta}$ '. 